NBER WORKING PAPER SERIES

\title{
CRISIS INNOVATION
}

Tania Babina

Asaf Bernstein

Filippo Mezzanotti

Working Paper 27851

http://www.nber.org/papers/w27851

\author{
NATIONAL BUREAU OF ECONOMIC RESEARCH \\ 1050 Massachusetts Avenue \\ Cambridge, MA 02138 \\ September 2020
}

The authors would like to thank Brian Beach, Shai Bernstein, Charles Calomiris, Bill Collins, Pranav Desai, Katherine Eriksson, James Feigenbaum, Michela Giorcelli, James Fenske, Alex Field, Walker Hanlon, Christian Helmers, Taylor Jaworski, Chad Jones, Pete Klenow, Naomi Lamoreaux, Gustavo Manso, Kris Mitchener, Petra Moser, Ramana Nanda, Tom Nicholas, Santiago Perez, Bitsy Perlman, Sarah Quincy, Tom Schmitz, Amit Seru, Chenzi Xu, Ting Xu, Nicolas Ziebarth, Ariell Zimran and seminar participants at the Amsterdam Business School, Auburn University, University of Colorado at Boulder, Columbia Business School, Hass School of Business, 2019 HEC Workshop on Entrepreneurship, Michigan State University, 2019 Minnesota Junior Finance Conference, 2019 Labor and Finance Group, Northwestern University Economic History Festival, 2020 NBER SI DAE, Owen Graduate School of Management, Rutgers University, Stanford University, Tuck School of Business, 2019 UT Dallas Finance Conference, University of Virginia, and 2020 Virtual Economic History Seminar. All errors are our own. The authors have no relevant funding or competing interests to disclose. Belinda Chen, Tam Mai, Nicholas Jeanrenaud, and Anna Schetkina provided outstanding research assistance. The views expressed herein are those of the authors and do not necessarily reflect the views of the National Bureau of Economic Research.

NBER working papers are circulated for discussion and comment purposes. They have not been peer-reviewed or been subject to the review by the NBER Board of Directors that accompanies official NBER publications.

(C) 2020 by Tania Babina, Asaf Bernstein, and Filippo Mezzanotti. All rights reserved. Short sections of text, not to exceed two paragraphs, may be quoted without explicit permission provided that full credit, including $\odot$ notice, is given to the source. 
Crisis Innovation

Tania Babina, Asaf Bernstein, and Filippo Mezzanotti

NBER Working Paper No. 27851

September 2020

JEL No. G01,G21,N12,N22,N32,O3

\begin{abstract}
The effect of financial crises on innovation is an unsettled and important question for economic growth, but one difficult to answer with modern data. Using a differences-in-differences design surrounding the Great Depression, we document that local distress caused a sudden and persistent decline in patenting by the largest organizational form of innovation at this time-technological entrepreneurs. Parallel trends prior to the shock, evidence of a drop within every major technology class, and consistent results using distress driven by commodity shocks—all suggest a causal effect of distress. Despite this, we find that innovation during crises can be more resilient than it may appear at first glance. First, there is no observable change in the number of future citations, despite the decline in the number of patents filed. Second, the shock is in part absorbed through a reallocation of inventors into firms, who over the long-run produce patents with greater impact. Third, the results reveal no immediate brain drain of inventors from the affected areas. Overall, we demonstrate that crises can be both destructive and creative forces for innovation, and provide the first systematic evidence of the role played by the Great Depression in the longrun organization of innovative activity.
\end{abstract}

Tania Babina

Assistant Professor of Business

Columbia Business School

3022 Broadway, Uris Hall 814

New York, NY 10027

tania.babina@gsb.columbia.edu

Asaf Bernstein

Leeds School of Business

University of Colorado at Boulder

Campus Box 401

Boulder, CO 80309

and NBER

asaf.bernstein@colorado.edu
Filippo Mezzanotti

Kellogg School of Management

4389 Global Hub

2211 Campus Drive

Evanston, IL 60201

filippo.mezzanotti@kellogg.northwestern.edu

A data appendix is available at http://www.nber.org/data-appendix/w27851 
"Many firms [of the 1930s] run by inventor-entrepreneurs were either acquired or driven out of business" Landes et al. (2012)

"1929-1941 were, in the aggregate, the most technologically progressive of any comparable period in U.S. economic history" Field (2003)

How do crises affect innovative activity? Theoretically, a financial crisis may create important setbacks in the production of innovation and a "missing generation" of highly productive entrants which could reduce business dynamism and growth (Hall 2015, Gourio et al.2016). Alternatively, periods of economic duress may represent an opportunity to reshape innovation efforts towards more efficient organizational forms and higher-impact projects (Schumpeter, 1942; Caballero et al. 1994; Manso et al., 2019). Existing empirical evidence so far is mixed. For example, the Great Depression - one of the largest financial crisis in history — was associated with a large drop in the aggregate number of patents filed (Lamoreaux et al., 2009). Yet, Field (2003) and Kelly et al. (2018) show evidence of a high average quality of innovations in this period. In this paper, we show that such findings are not necessarily mutually exclusive. We document that crises can be persistently devastating for technological entrepreneurship, but at the same time promote organizational changes that may positively affect the development of new innovation.

We study this question in the context of the Great Depression. On the one hand, this setting helps resolve some of the empirical challenges existing in modern data. Firm dynamics are slow-moving Luttmer 2012), making it difficult to evaluate a crisis without a sufficiently long time span following the event. The long post-Depression period not only helps us overcome this challenge, but it also allows us to examine the persistence of potential changes in innovative activity. Furthermore, current innovative activity, and especially technological entrepreneurship, is concentrated in just a handful of locations (Jaffe et al., 1993 Moretti, 2019), making it hard to find meaningful variation that could be used to cleanly identify the effect of a shock that can account for reallocation. Prior to the 1930s, innovation produced by independent inventors - outside of the boundaries of a traditional firm - was the predominant form of patenting, and pockets of technological entrepreneurship were ubiquitous across the U.S. (Lamoreaux et al. 2009). On the other hand, the period around the Great Depression is also uniquely interesting for economists. For instance, historians have written extensively about the deep transformation in the organization of innovation that has taken place in the U.S. around the 1930s, as firms took over independent inventors as the main source of patenting. Despite the importance of these changes, the direct empirical evidence connecting this shift to the Great Depression is lacking (Mowery and Rosenberg 1989 Lamoreaux et al. 2009, Kenney 2011). 
We put together two main datasets to study how the Great Depression affected subsequent short- and long-run innovative activity. We first develop a new county-level measure of technological entrepreneurship based on independent patenting, spanning more than a century. We document that our county-level measure of technological entrepreneurship is highly correlated with the U.S. Census-based measures of entrepreneurship at the local level and in the time-series (in periods when both data are available). There are several benefits to our data. First, this new measure enables us to study the drivers of entrepreneurship prior to the availability of modern data, which start in the 1980s. Second, the geographic variation in the data allows us to use spacial variation in economic distress during the Great Depression to examine the effect of the crisis on county-level technological entrepreneurship, and compare this response to the behavior of firms during the same period. Third, county-level data let us capture local reallocation effects, which are missed when using firm-level data and, theoretically, represent an important margin of adjustment during crises. Finally, we can measure patents' long-run influence on future generations of innovations that build on past patents though patent citations.

The second key dataset we construct is longitudinal inventor-level data linking inventors that file patents in 1905-1945 across four decennial full-count U.S. Censuses. These new data allow us to measure potential reallocation effects in response to the shock by tracking inventors across different organizations of innovation and geographic space. Moreover, the comprehensive nature of these patent-Census matched data allows us to document the differences in personal characteristics and innovation produced by inventors inside firm boundaries (firm patents) as well as outside (independent patents) during the first half of the 20th century. For example, we show that independent inventors are much more likely to be immigrants as compared to inventors working within firms, which is consistent with immigrants being more entrepreneurial (Kerr and Kerr, 2020).

We then examine whether the crisis affected subsequent innovation based on the number of patents filed. To identify the effect of the crisis, we use a differences-in-differences design that exploits countylevel variation in bank suspensions during the Great Depression, which proxy for the local severity of the crisis. Our specification includes state-time fixed effects to flexibly control for contemporaneous changes in state-level policies and local business cycles, and county fixed effects to control for unobserved timeinvariant heterogeneity across counties. Using this setting, we document that the local disruption from the crisis predicts a sudden decline in patenting by technological entrepreneurs, but no aggregate local effects on firm patenting. For instance, counties that experienced bank distress during the Depression 
saw patenting by independent inventors decline $13 \%$ more than non-affected counties in the same state. Parallel trends prior to the shock, no reduction in firm patenting, evidence of a drop within every major technology class, and similar results using alternative shocks to local financial markets - all suggest that the effects are causal.

Even though the crisis itself was relatively short-lived, the effects on technological entrepreneurship appear to be permanent-lasting for every decade for the next 70 years. Overall, these findings of a substantial and persistent decline in patenting by independent inventors are potentially concerning given that independent patents were the major source of new technologies in the early 20th century, and were, on average, of higher quality than firm patents (Lamoreaux et al., 2009; Nicholas 2010). Hence, one might naturally conclude that crises are purely destructive forces for innovative activity.

However, despite the negative effects on the quantity of independent patenting, additional analysis suggests that innovation was more resilient than it might appear at first glance. First, despite the decline in the number of patents filed, distressed areas do not see any observable change in aggregate (future) patent citations. Consistent with this finding, we document that the average quality of independent inventors' patents actually increases in distressed areas during the Great Depression and high-quality patents are mostly unaffected. This evidence suggests that independent inventors with high-quality projects are still able to obtain financing during the Depression and experience limited disruption. Second, the shock is in part absorbed through a reallocation of independent inventors into firms, which were less affected by the shock. Using inventor-level panel data, we find that among serial inventors-individuals that patented both before and after the Great Depression-independent inventors in counties characterized by higher bank distress are more likely to patent within firms during the 1930s. This reallocation of human capital may explain our additional findings that, in the long-run, firms in more affected areas saw an increase in overall patented innovation as well as in the aggregate quality of innovation. Third, the results reveal no significant brain drain of inventors via out-migration from the affected areas.

To conclude, we provide some suggestive evidence on the mechanisms that may explain the relationship between bank distress and innovation. While evidence on underlying mechanisms is more speculative, and not critical for our contribution, it may still be of interest since we do find evidence more supportive of some channels than others. For example, growth in local retail sales during the Great Depression-a key variable used to proxy for local demand shocks (Fishback et al. 2001) — does not predict significant changes in local innovation. Instead, the results are more likely explained by the link that bank distress 
had to local financing or labor markets for technology entrepreneurs. On the one hand, this channel may not be surprising, since sources of capital for developing innovation were local, but secondary markets for technology and patents were national in scope (Lamoreaux and Sokoloff 2001a). On the other hand, this result may appear puzzling, because bank lending was not the dominant source of capital for independent inventors (Lamoreaux et al. 2006). One possible explanation is that the contraction in bank activity is connected to a disruption of the ecosystem providing financing to technology entrepreneurs. As suggested by (Lamoreaux et al., 2006), and as it is often the case for entrepreneurs today, independent inventors relied heavily on local wealthy individuals to raise capital for developing or bringing to market their technology. In that period, distress in the local banking sector was intimately tied to the same factors that affected the fortunes of local wealthy investors. Hence, bank distress may have been directly or indirectly related to the ability of these individuals to invest in new risky ideas, perhaps permanently disrupting these networks.

Consistent with this narrative, we use a unique data on fundraising by Illinois firms in the preDepression period (Akkoyun, 2018) to show that local investors were indeed a key source of financing for early-stage tech companies. Furthermore, we provide descriptive evidence that wealthy investors in the interwar period were generally highly exposed to shocks to local markets, and in particular to real estate. Consistent with this idea, we show that we can replicate our main findings - on both the quantity and quality of innovation - using an alternative approach that more directly measures a shock to local real estate wealth. In particular, following Rajan and Ramcharan (2015) and Jaremski and Wheelock (2018), we exploit the variation in local property values induced by the commodity price boom and bust related to World War I (WWI). This evidence is consistent with shocks to local capital playing a critical role in the shift in innovative activity triggered by the Great Depression. Furthermore, the use of shocks in commodity prices following WWI, instead of bank distress in the early 1930s, also provides additional evidence that our overall findings are not driven by reverse causality.

Overall, our findings suggest that financial crises are both destructive and creative forces for innovation, and we provide the first systematic evidence of the direct role distress from the Great Depression played as a catalyst for long-term changes in innovative activity. Surprisingly, we document that innovation was resilient in the face of one of the largest financial crises in the U.S. history, suggesting that it is likely to be even more so during milder economic recessions. 


\section{Related Literature}

This paper makes contributions to several strands of literature. First of all, we contribute to the vast and still growing literature exploring the determinants of innovation activity. While a complete review is beyond the scope of this paper, these determinants include the role of immigration (e.g., Kerr and Lincoln, 2010; Moser et al., 2014), taxation (e.g., Akcigit et al. 2017), intellectual property laws (e.g., Moser, 2005), government investments in R\&D (e.g., Gross and Sampat, 2020; Moretti et al., 2019), bank credit (e.g., Bai et al., 2018), vertical and horizontal boundaries of the firm (e.g., Seru, 2014; Frésard et al., 2020), competition (e.g., Aghion et al., 2005), and exposure to innovation (e.g., Bell et al., 2019), among other things. Our findings on the dark and bright side of crises add other important factors to consider in the drivers of innovation. Specifically, our results complement a body of work examining the effects of large economic shocks on innovation. In the context of a financial crisis, Nanda and Nicholas (2014) shows that among firms owning R\&D labs before the Great Depression, bank distress had negative effects on their patents in terms of both the quantity and quality of innovation 1 When it comes to recessions more generally, Manso et al. (2019) builds a model and estimates that economic downturns can trigger more exploitative innovations. We complement these studies in the following ways. We are the first to examine how a crisis affects the quality and quantity of innovation produced by technological entrepreneurs and by all inventors. Second, we examine the long-term effects (10 years or later) of a crisis on subsequent innovation. Third, our new county-level and individual-level patent data allow us to document the importance of reallocation effects in response to a crisis.

Our paper also contributes to the literature studying the organization of innovation. While modern patenting is dominated by firms, this organizational structure of innovation is neither historically ubiquitous Nicholas, 2010; Kenney, 2011, Landes et al., 2012) nor clearly theoretically dominant Aghion and Tirole 1994, Gromb and Scharfstein 2002, Garcia-Macia et al., 2019). During the period examined, independent inventors were at the forefront of the technological frontier and in many dimensions were akin to technology entrepreneurs today (Lamoreaux and Sokoloff $2001 \mathrm{~b}$, Nicholas 2010$)^{2}$ : $^{2}$ Within this literature, our paper adds to our understanding of how economic crises can be a catalyst for the way in which innova-

\footnotetext{
${ }^{1}$ This is also related to Huber (2018), which demonstrates similar firm-level effects on patenting rates during the Financial Crisis by exploiting variation in German firms' exposure to a large bank's lending cut. Huber (2018), however, does not examine changes in the quality of innovation, which isn't surprising since innovation is not the primary focus of the paper.

${ }^{2}$ In fact, similar to start-ups today, independent inventors were early-stage organizations that developed new technologies in order to raise money either from external investors or sell the technologies to larger firms.
} 
tion is organized. Caballero et al. (1994) have formalized and extended a long-argued point that recessions could have positive effects by fostering "creative destruction" and, therefore, helping the reallocation of investment towards more productive use. In fact, even more generally than just "liquidationist-style" arguments, crises could cause an overall shift in the organizational form of innovation or in the incentives for existing inventors, which alter the impact of surviving patents. Our evidence is consistent with these types of mechanisms. Our results suggest that while periods of severe and prolonged financial distress may be followed by declines in the quantity of patents filed by start-up like enterprises, innovation as a whole appears to be quite resilient. We document a rise in allocative efficiency towards higher quality inventions and a shift in the organizational form of innovation production. Our analysis suggests that large economic shocks can facilitate the reallocation of resources across different organizational forms of innovation. In particular, our evidence suggests that the distress induced by the Depression affected the way innovation moved from independent inventors to firms.

Understanding how these transitions may take place can generate important insights into the determinants of business dynamism. In this area, several scholars have recently expressed concern about declines in new firm entry (Bassetto et al., 2015, Siemer, 2016; Moreira, 2016), slow-downs in technological advancement (Hall 2015), and declines in productivity (Duval et al., 2020) in the aftermath of the Great Recession. These sorts of concerns in the fallout from major financial crises are not new, however. In fact, Schumpeter (1934) considers just such concerns in the aftermath of the Great Depression, but also concludes that "depressions are not simply evils, which we might attempt to suppress, but-perhaps undesirable_-forms of something which has to be done, namely, adjustment to previous economic change".

Our results also contribute to the economic history literature, by helping to reconcile seemingly contradictory findings of the destructive nature of the Great Depression and the evidence in Field (2003) and Kelly et al. (2018) that describe the aftermath of the Great Depression as an era of incredible technological progress and innovation. While we find that the unfolding of the Depression led to a contraction in the amount of patenting filing by technology entrepreneurs, our results on the quality of innovation suggest that inventors with high -quality projects were in large part unaffected by the crisis. Furthermore, our evidence on cross-organizational migration suggests that reallocative forces were critical in understanding the full response of innovation to the crisis. These findings would not be possible to achieve without data encompassing the full universe of patents, especially by independent inventors, and 
an empirical design that allows for identification of the long-run local general equilibrium effects. Our results suggest that all these forces are crucial in accurately assessing the effects of such crises on overall innovative activity $\left.\right|^{3}$

Our work also contributes to an even broader discussion in the economic history literature on the role that the disruptions to the financial system played in instigating the Great Depression, and its consequences for economic outcomes. Economists have typically focused on the effects of monetary policy (Friedman and Schwartz 1963; Richardson and Troost 2009, Gorton and Metrick 2013), demand declines (Temin et al. 1976, Romer, 1993), international flows (Eichengreen, 2004), shocks to productivity (Cole and Ohanian, 2007), and bank lending amplifiers (Bernanke, 1983; Gorton et al., 2019, Mitchener and Richardson, 2019). In many ways, the Great Depression has been extensively used as a laboratory to examine the real effects of banking shocks, and we add another component to that discussion - the effects on aggregate local innovation. Recent empirical work has shown that bank failures had large negative effects on income growth (Calomiris and Mason, 2003), business revenues (Ziebarth, 2013), business failures (Babina et al., 2017), and employment (Benmelech et al., 2017; Lee and Mezzanotti, 2017). We document that there were also clear effects from local distress on technological entrepreneurship as well as the total innovative local activity. Unlike most of the prevailing literature though, we also document a "bright side" to the Great Depression in the form of creative destruction.

\section{Historical and Institutional Background}

\subsection{The Organization of Innovation in the Early 20th Century}

In the early 20th century, U.S. innovation was in large part created within two main organizational forms: firms (often with R\&D labs) and independent inventors. While the boundaries between these two types of organizations may have been blurry in some dimensions, there are several aspects in which these two organizational forms differed substantially. First, they financed themselves differently. In general, independent inventors financed their inventions either using personal resources or raising equity financing from local wealthy individuals who played a role similar to modern angel investors Lamoreaux et al. 2009 Nicholas 2010). In the quest for new financing, inventors relied heavily on the connections to local

\footnotetext{
${ }^{3}$ In that respect our findings are supported by Lamoreaux et al. (2009) which shows specific instances when distress from the Great Depression led to shifts of recent potential technological entrepreneurs, graduates of Case Western University, into firms.
} 
bankers and businessmen (Lamoreaux et al. 2006, Kenney 2011). Importantly, in this market, financing was inherently linked to a specific project or business idea (Lamoreaux et al. 2006).

In contrast, the financing of innovation by established firms was less dependent on the local networks of investors. Similar to most modern corporations, it is generally accepted that a large part of established firms' R\&D investment was covered by internally generated cash flows (Hall and Lerner, 2010). At the same time, firms raised funding through a variety of mechanisms, such as the sale of equity securities (Nicholas 2008; Lamoreaux et al. 2009), issuance of bonds (Jacoby and Saulnier 1947) or borrowing from banks (Nanda and Nicholas, 2014). These sources were generally used to fund more traditional corporate activities (e.g. working capital, tangible investment), but access to these markets—by affecting the general financial condition of a company - could have had implications for innovation decisions.

The second key distinction between the two organizational forms was their business objectives and strategies. On the one hand, firms operating R\&D labs were primarily interested in commercializing the technology directly, either by creating new products or integrating the new technology into their preexisting portfolios. On the other hand, independent inventors developed new technologies or products to raise financing to start a business or to monetize inventions through the sale or licensing of patents.

In comparing independent inventors to firms, we also need to understand the dynamic connection between the two organizations. While not all independent inventors aimed to establish a firm, some of them did. Hence, patenting activity by independent inventors will always capture innovation happening outside of the boundaries of traditional firms, but will not always capture patenting made by early-stage enterprises. We later address this categorization issue by including into independent patents those that were assigned to firms with eponymous names (e.g., "Edison Electric Company").4

When discussing independent inventors, it is important to highlight the importance of this organizational form during the early part of the century. For instance, Nicholas (2010) shows that, in the 1920s, around $70 \%$ of all U.S. patents were attributed to independent inventors. At the same time, independent inventors were also important from a qualitative standpoint. Historically, some of the most impactful inventions were initially developed by independent inventors. Lamoreaux et al. (2009) and Nicholas (2010) find that over the 1900-1929 period, independent patents were, on average, higher quality than firm patents, as measured by future citations and the number of claims in the patent text. For example,

\footnotetext{
${ }^{4}$ Related to this point, we show that our results are robust to counting as independent inventor patents those patents that are assigned to a firm whose name contains the same name as an inventor(s) (Section 4.2).
} 
Lamoreaux et al. (2009) show that 33\% of a random sample of patents filed over 1928-1929 are cited by patents filed over 1975-2000 in the NBER patent data. This number is higher for independent patents (36\% receive future citations) and lower among patents filed by firms with R\&D labs (25 to $30 \%$ ). This evidence is consistent with the results in Kelly et al. (2018), who show that in the post Depression period, independent inventors represented a substantial share of breakthrough patents.

In light of these distinctions, there is a strong parallel between independent inventors in the early 20th century and technology entrepreneurs or start-ups in modern days. From a financial standpoint, they both heavily rely on external early-stage local investors as a key source of financing, at least after an initial phase of self-financing and bootstrapping. In this regard, as in the early 20th century, personal contacts and local investors' networks are still key for the process of raising funds (Shane 2008; Bernstein et al. 2016; Gompers et al. 2019) . $^{5}$ Moreover, the core investment thesis for both independent inventors in the 1920s and modern technology entrepreneurs is fairly similar: both are focused on the development of new technologies or products with the objective of either selling their innovations to an established company or raising financing to commercialize the product internally. Lastly, both organizations are important engines for the development of new ideas and technologies.

Therefore, while it is undeniable that several aspects of the organization of innovation have dramatically changed over the past century, it is also the case that the key economic features through which both firms and technology entrepreneurs operate have remained surprisingly stable. This parallel implies that a study of independent inventors may provide insights that can be useful to understand the process of innovation today. Furthermore, this parallel also suggests that measuring the activity of independent inventors at the local level could also proxy for the vitality of the local entrepreneurial environment. In modern data, the dynamism of local markets is typically measured by quantifying the amount of economic activity that is undertaken by technology start-ups (e.g. Guzman and Stern, 2016) or young firms more broadly (e.g. Haltiwanger et al., 2012). Similarly, a measure of technological entrepreneurship based on independent inventors captures the extent to which technology is developed outside of more mature firms. As such, the measure allows us to study drivers of local entrepreneurship over a very long time horizons and uncover the dynamics of entrepreneurial development across U.S. counties before modern U.S. Census data on new firms became available in the 1980s. Moreover, fine regional variation in patent

\footnotetext{
${ }^{5}$ In this regard, the key difference is that the financing of early stage enterprises today is relatively more institutionalized, because of the creation of organized angel groups (Kerr et al. 2011) and the growth of venture capital (Ante, 2008, Kenney 2011).
} 
data allows us to control for any aggregate or regional changes associated with patenting rules.

We perform two sets of analysis to examine whether our new measure of entrepreneurial activity is correlated with entrepreneurship rates in current data when both are available. Figure A.1 shows that independent innovation rates are correlated with the rates of employment in young (0-3 year old) firms. Moreover, we find a sizable correlation (0.5) between the county-specific rates of patents produced by independent inventors and employment in 0-3 year old firms, providing support for this alternative measure which is available to us during the period we study.

\subsection{Innovation during the Great Depression}

The Great Depression was one of the largest financial crisis in history, with almost a third of all banks suspended and a real GDP decline of 26\% (Margo 1993 Richardson 2007). The concurrent disruption of banking activities and real economic growth were more than just coincident. At this time, financing was a more localized affair because of regulatory and technological constraints Mitchener and Wheelock 2013). When banks failed, this caused massive disruptions in the ability of local firms to obtain financing.

In aggregate, the period around the Great Depression was also one of substantial shifts in innovative activity. For instance, Figure 1 shows that a decline in annual patenting happened within virtually all major technology classes right around the Great Depression. Furthermore, this decline is almost entirely driven by a reduction in patenting coming from independent inventors. To start examining this issue, we plot in Figure 2 the number of patents filed annually by independent and firm inventors in the first half of the 20th century. This figure shows that, while independent inventors accounted for the majority of patenting in the 1920s, this changed quickly around the Great Depression. In particular, the number of patents filed by independent inventors fell by almost $50 \%$ during the years of the Depression. As a result, patents by independent inventors were surpassed by patents filed by companies. This shift was also persistent, with independent inventors never catching back up to firms, consistent with evidence in Nicholas (2010). This secular decline seems unlikely to be explained by institutional changes in the patent system, which was relatively stable over this period. ${ }^{6}$

\footnotetext{
${ }^{6}$ One potential remaining concern is that patent costs may have increased during this period, crowding out independent inventors more than firms. However, this hypothesis is not supported by data on the actual costs of patenting. As shown in De Rassenfosse and van Pottelsberghe de la Potterie (2013), the cost of patenting during this period was pretty low (around $\$ 500$ in 2005 dollars). Nominal fees are stable during this period, and they only increased after the 1960s. There is only a small increase in real fees in the early 1930s due to deflation. However, this increase - on top of being relatively small-is also short-lived and therefore unlikely to explain the long-term persistence of our findings.
} 
Clearly, there could be several explanations for these trends. One commonly held view is that this shift reflects a change in the nature of technologies developed during this period (Teece David 1988; Hughes 2004 Lamoreaux and Sokoloff 2005). In particular, as the process of developing and using technologies became more capital intensive and complex, firms became a relatively more efficient organizational form. For this argument to hold, the standard assumption is that firms - for both institutional and economic reasons - are in a better position to finance larger investments over long periods of time. Consistent with this argument, Figure 2 shows that the decline in independent patents starts before the Great Depression, even if the larger part of the drop happens exactly during the Depression period.

However, this simple hypothesis fails to explain the full dynamics of the contraction in independent inventors' patenting during this period. As pointed out earlier, much of the the decline in patenting around the Great Depression happened roughly at the same time across all main technologies (Figure 1). Since it is not likely that technological shocks occurred across all industries nearly simultaneously (and concurrently with the Great Depression), an explanation that is only technology-based will likely fall short to rationalize all of the contraction in independent patenting. We are not claiming that technology considerations were not important to understand the decline. They almost certainly were. Instead, we are simply highlighting that a more complete theory requires something else to understand the sudden decline in independent inventing during this period.

In this context, another view is that the economic distress from the Great Depression contributed to the demise of independent inventors. In particular, several economic historians have hypothesized that shocks to local financing brought about by the Depression may have led to disruptions of local investors' networks and reductions in willingness to supply early-stage financing. For example, Kenney (2011) writes that "the obstacle to establishing these new firms was a shortage of risk capital, which they believed was due to the changes caused by the Depression that discouraged wealthy individuals from risking their capital in untested firms.'17 In addition, Lamoreaux et al. (2009) concludes that "the subsequent dominance of large firms seems to have been propelled by a differential access to capital during the Great Depression."

Importantly, these two explanations are not mutually exclusive. While we believe that technology alone cannot explain the sudden decline in independent inventions around this period, this force could very well play an important role in explaining the persistence of the decline and the speed of transition between

\footnotetext{
${ }^{7}$ A Wall Street Journal editorial on January 24th, 1938 also noted that "there is no 'venture capital' to speak of [in the U.S. economy] because there is no venture spirit on the part of capital owners or those who normally would be borrowers of that capital."
} 
the two organizational forms. Therefore, our tests are designed to examine whether the disruption brought about by the Great Depression was a catalyst for the decline in the activity of technology entrepreneurs and its relative persistence, keeping constant overall trends in technology. As a result, despite the evidence of shifts in aggregate statistics and relatively localized financing at this time, it is theoretically possible that there may have been no national aggregate effects of the Great Depression on innovation relative to the long-run changes that would have happened solely because of the technology shift. However, even if this were the case, our findings would have important implications. First, the shock would influence the timing and the speed of the transformation, which is crucial for understanding the welfare impact of the structural change. Second, the crisis may also affect the distributional effect of the shock. In particular, to the extent that we might find persistent differences in the county-level analysis, this will suggest that the way the Depression unfolded had a persistent impact in determining the regions where technological entrepreneurship persisted and the way innovation was organized locally in these areas.

\subsection{Bank Distress and Technology Entrepreneurs}

While the notion that bank distress could affect the innovative process is intuitive, the exact mechanism through which this phenomenon could take place is more ambiguous. Previous research has established that bank lending was not a major source of financing for independent inventors. One exception may be the innovation activity that was undertaken within established firms (Nanda and Nicholas, 2014) 8 However, distress in the banking sector may still have affected the funding of technology entrepreneurs via more indirect channels. One hypothesis is a distress-driven decline in demand: as local firms suffer because of the contraction in lending, the demand for technologies developed locally may decline. While this is not an unreasonable hypothesis, it seems likely that this demand-driven explanation will fall short in explaining our results, since the market for technologies at the time was already quite developed and demand was in large part national or regional (Lamoreaux et al. 2006, 2009). Despite this fact, we will explore directly this hypothesis in our empirical analysis.

Alternatively, we hypothesize that bank distress could impair the supply of financing coming from wealthy individuals acting like "angel investors" in the local market.9 This disruption of local "angel

\footnotetext{
${ }^{8}$ In $\sqrt{\text { Nanda and Nicholas }}(2014)$, the concentration of effects in industries more dependent on external finance are consistent with Mowery and Rosenberg (1989), who document that firm investments in R\&D facilities and personnel actually rose during the Depression.

${ }^{9}$ In our setting, bank distress is not used because of the direct effect that banks can have, but because bank distress can proxy for several sources of distress to local wealth. As a result, we do not think that our setting is likely to contribute
} 
financing" could happen for several reasons. First, banks were known to be central nodes of information transmission between local inventors that needed financing and wealthy individuals, such as bank clients, local businessmen, landowners, and banks' officers and directors themselves, who were willing to back the inventors (Lamoreaux et al., 2006). Hence, failures of local banks can sever information flows and destroy relationship capital, which are important pieces of the local innovation ecosystem. This effect in principle could affect any type of organization, but it should have a larger impact on independent inventors, since this type of organization has fewer financing alternatives, receives financing on a project-by-project basis, and is more dependent on local networks to secure financing.

Second, local bank distress could be linked to the reduced ability or willingness of local wealthy individuals to invest in risky technological projects. This second mechanism requires two assumptions to be economically relevant. The first assumption is that the wealth of local investors needs to be exposed to local bank distress. Many financial-backers were business owners of established companies in the area, and therefore their fortunes were directly tied to those of local banks. At the same time, wealthy individuals were likely to have a relatively substantial part of their wealth invested in real estate, which was also sensitive to many of the same conditions which could affect the local banking sector. To provide evidence for this hypothesis, we examine the Study of Consumer Purchases in the United States (1935-1936), which provides a partial but unique outlook on the portfolio of individuals during this era. Using these data, we provide several stylized facts that are in line with our narrative. In particular, we find that even among business owners, the exposure to stocks and bonds - as examples of assets that are not local and therefore less affected by the local distress - is relatively small. Only $10 \%$ of business owners obtain any income from these securities. Furthermore, exposure to real estate is much larger in magnitude: overall, $42 \%$ of business owners report owning at least 50 acres of land during this time.

The second assumption is that investors in technology entrepreneurs need to be local, and, therefore, affected by the same economic shocks as the inventors. While direct evidence of this hypothesis is hard to find, a large body of historical work suggests that many financial-backers of technology entrepreneurs were business owners of other companies in the area (e.g. Lamoreaux et al., 2006). To examine this hypothesis, we digitized investment prospectuses of about one hundred early-state technology firms that were planning to sell securities in Illinois between 1919 and 1924, as discussed in Akkoyun (2018) 10 In

substantially to the debate characterized by Bernanke (1983) and Friedman and Schwartz (1963) on the direct role of disruptions of intermediation in explaining the depth of the recession in 1929-1933.

${ }^{10}$ We kindly thank Cagri Akkoyun for sharing with us the original copies of the documents he has collected from the 
large part, these firms are early-stage technology companies, and, therefore, the investors reported at this point are likely to reflect those individuals that invested in the business at its infancy. We identify potential investors by looking at firms' directors that are also not officers of the company 11 Of the 114 individuals that we identify as early investors, and for which we have information of the city of residence, we find that in $66 \%$ of cases these individuals live in the same city in which the company's headquarters are located, supporting the hypothesis that most of the investors in early-stage innovation were local.

The wide prevalence of early-stage investors who could support technological entrepreneurs in these areas might partly explain why during the 1910s and the 1920s independent inventors were responsible for the majority of patents in Illinois' major innovation hub - Cook County, and, in particular, Chicago. As shown by Mitchener and Richardson (2019), almost 25\% of all banks outside Chicago deposited funds in Chicago's reserve city banks, due to the pyramiding structure of bank reserves which was leftover from the national banking period. With the onset of the Great Depression, many banks felt liquidity pressures and withdrew their funds from Chicago's banks causing a massive strain on their local financial system. In fact, Chicago had the highest bank failure rate of any urban area in the U.S. (Guglielmo 1998), with $82 \%$ of banks in mid-1929 gone by mid-1933 and more than $60 \%$ of deposits withdrawn Calomiris and Mason 1997; Postel-Vinay 2016). The result was a severe financial crisis in Chicago and the surrounding areas. What started with banks going under quickly spilled over more broadly into overall economic turmoil (Bernanke 1983). In our data, we find that innovation also changed dramatically in Cook County during this period of economic distress. Despite an increase in patents filed by independent inventors in Cook County in each of the two decades preceding the Great Depression, independent patents filed would plummet by $47 \%$ in the 1930 s, while those by firms would fall only $9 \%$. Independent patenting would continue to fall in each of the following three decades, while firm patenting largely recovered to pre-crisis levels. ${ }^{12}$ Despite the large decline $(29 \%)$ in total patenting in the 1930 s relative to 1920 , total future citations over the next 70 years from patents filed during this period would actually rise $34 \%$. While a single county is obviously insufficient evidence on its own, it is certainly consistent with better identified evidence we will provide on the effects of economic distress on innovative activity in the aftermath of the

\footnotetext{
Illinois Securities Division.

${ }^{11}$ We exclude officers because we believe these individuals are more likely to be founders, rather than early investors. This exclusion actually works against us, since officers tend to reside in the same location as the firm.

${ }^{12}$ This appears to occur for both - the entry and exit of inventors and among inventors patenting in both decades. Among all U.S. counties in our sample, Cook County actually has the most serial inventors who patent independently before the Great Depression, but in firms after.
} 
Great Depression and the importance of disruptions to local investor capital as a driver of that shift in patenting patterns.

\section{$3 \quad$ Data and Descriptive Statistics}

\subsection{Historical Patent Data}

We use data on the near universe of United States Patent Office (USPTO) patents, representing over 9 million patents from 1836-2016, which include filing and grant date, inventors' and assignees' names (if assigned), and their locations. These input data are provided to us by Berkes (2016), and we perform extensive cleaning and standardization of these patent data 13 Throughout the analysis, we use a patent's filing year because this date is closer to the actual date of invention as compared to the grant year. For all patents, we obtain patents' technology classification (e.g., "Electricity") from the USPTO's Cooperative Patent Classification (CPC). For patents filed in 1910-2016, we also have information on citations coming from patents filed during the same period ${ }^{14}$ Restricting attention to U.S. inventors or assignees in our main sample period of 1910 to 1949 gives us 1.4 million patents. Among these patents, 98\% have the inventor's city and state information (which are crucial to aggregate to county-level data), $99 \%$ have patent technology classification, and $73 \%$ are cited at least once. The resulting dataset compares in its comprehensiveness to the data in Akcigit et al. (2017) and Sarada et al. (2019), who characterize inventors in historical patent data. ${ }^{15}$ Relative to Nanda and Nicholas (2014) who looked specifically at the impact of the Great Depression on innovation by firms with R\&D labs, our dataset incorporates patents produced by independent inventors (who produced $55 \%$ of patents in our sample) and patents produced by firms without R\&D labs, 16

\footnotetext{
${ }^{13}$ We are incredibly grateful to Enrico Berkes for sharing this data with us. For more details on the impressive construction of these data please see Berkes (2016). The extensive report on the patent data cleaning, standardization, and matching to county-level data is available in Online Appendix A on Tania Babina's website.

${ }^{14}$ As discussed in Berkes (2016), while the quality of the reporting of cited patents improves over time (in particular after 1947), we are still able to obtain some information on cited patents in the early part of the sample by extracting patent numbers mentioned in the patent text. Furthermore, it is important to point out that our baseline analysis uses all future citations by patents filed through 2016 (i.e., not only citations from patents published during the Great Depression) - this long window allows us to capture important innovations on which the future generations of patents are built. In our baseline analysis, we do not scale a patent's citations count by the number of citations in its technology class and filing time for a number of reasons. First, the interpretation of the summary statistics of unscaled patents is more intuitive. Second, the results are the same when we do scale, as discussed in Sections 4.2 and 5.2 Finally, the inclusion of state-by-time fixed effects in the main analysis essentially scales the citations by the timing of filling, as discussed in Hall et al. (2001).

${ }^{15}$ See Andrews 2019 for the discussion and comparison of historical patent data produced by different teams of researchers.

${ }^{16}$ Unfortunately, we do not have access to the data on firms with R\&D labs and hence unable to estimate the marginal increase in the sample due to the inclusion of patents by firms without R\&D labs.
} 
We separate U.S. patents in two groups: independent patents and U.S. firm patents. The independent inventors' patents are usually either unassigned, assigned to the inventor, or assigned to other individuals (e.g., angel investors); while patents assigned to firms are usually produced by inventors employed by firms with in-house $R \& D$ labs who would have been contractually obliged to assign their inventions to their employers $($ Lamoreaux and Sokoloff $2001 b$ : Lamoreaux et al. 2009 , Nicholas 2010$)$. Thus, we define independent patents as those granted to inventors residing in the U.S. that were either unassigned or assigned to individuals at the time of the patent grant date; and we define U.S. firm patents as those that were assigned to a U.S. company at the time of the patent grant date ${ }^{17}$ Figure A.2 shows an example of an independent patent - the famous light-bulb invention by Thomas Edison; while Figure A.3 shows an example of a patent assigned to a U.S. firm (i.g., "General Electric") at the time of the patent grant.

Since the financial markets for funding early-stage innovations were highly localized, a county-level geography roughly identifies the physical proximity of innovators and local investors. We match countylevel information to inventors' city-state locations. We are able to match $98 \%$ of patents with city-state information. We then create panel data by aggregating patents at each county-period for all U.S. patents, independent U.S. patents, and U.S. firm patents. For all three patent categories, we calculate countylevel measures of the number of patents, the number of future citations citing those patents, and the average number of future citations measured as total citations over the number of patents, which are all log-transformed in our regression analysis.

\subsection{Bank Distress Data}

Our measure of bank distress follows much of the literature (e.g., Calomiris and Mason 2003) in using Federal Deposit Insurance Corporation (FDIC) county-level annual reports on active and suspended banks and their deposits from 1920-1936. These data are unavailable in the states of Wyoming, Hawaii, and Alaska, and in the District of Columbia, and do not distinguish bank failures from bank suspensions.

\footnotetext{
${ }^{17}$ To identify firm patents, we build a long list of search words that are associated with firm patents and use this list in a regex approach to identify firm names. For example, we mark a patent as assigned to a firm if the assignee's name includes either of these types of words: a) company abbreviations (e.g., "corp" or "corporation"); b) words related to industries (e.g., "agricultural" or "automotive"); c) words related to geography (e.g., "american" or "east"). Using random sampling, we manually verified that: a) these search words produce the desired outcomes and identify patents assigned to firms; and b) among patents that are assigned, but not assigned to firms, 99\% are assigned to an individual. Moreover, using a regex approach, we also identify patents that are assigned to universities or the U.S. government. Consistent with Fleming et al. (2019), these categories represent a small fraction of total patents over our sample period (university patents comprise less than $0.1 \%$ patents and U.S. government-assigned patents represent less than $0.2 \%$ of patents, most of which are filed during WWII). Including or excluding these categories in either independent or firm patent counts have no measurable effect on our findings.
} 
However, Calomiris and Mason (2003) argue that these shortcomings do not interfere with identifying bank distress empirically. We use 1930 as the starting year for our banking sector distress indicator since it was not until at least 1930 that banks began to fail in large numbers, destroying relationship capital and access to finance (Bernanke 1983, Calomiris and Mason 2003).

Suspensions and failures of banks from 1930 through 1933 proxy for the local severity of the Great Depression. We indicate that a county is in distress during the Great Depression if there is at least one bank suspended in that county from 1930-1933, which represents $71 \%$ of all counties. This measure provides a relatively simple intuition for the interpretation of any observed treatment effects and is our primary measure of distress throughout the paper 18 However, our results are robust to alternative definitions of the treatment, as discussed later on. Building on Akcigit et al. (2017), we match bank distress data to the county-level panel data using the location of the first inventor. During this match, we lose two percent of U.S. patents because not all counties have bank distress data. After all these steps, our data contain about $94 \%$ of the 1.4 million patents in the initial sample. Table 1 presents summary statistics for the county-level data used in the analysis and shows that counties with bank suspensions during the Great Depression are somewhat larger than an average county, but have similar rates of the retail sales decline during the Great Depression and 1937 unemployment rates.

\subsection{Inventor Panel Data}

While county-level patent data is well-suited to measure how local distress affects aggregate local innovation, this level of analysis cannot speak to the micro-mechanisms driving aggregate changes in patenting. For example, aggregate changes can be driven through either migration of inventors across different organizational forms of innovation (e.g., from patenting independently to working for firms) or across geographic space (e.g., move from more distressed to less distressed areas). To examine such mechanisms, researchers would need access to longitudinal data on inventors and their place of inventing. However, the USPTO does not assign inventors a unique identifier, and linking inventors by name across patents is not sufficient to match individual inventors across time: some common names are recurrent across decades and counties, and potentially refer to different people who held the same name. Moreover, the commonly used modern methods of inventor disambiguation (e.g., Li et al., 2014) using additional variables such

\footnotetext{
${ }^{18}$ Furthermore, this measure helps assuage concerns of data quality in the measurement of bank distress, as it is very unlikely that misreporting would affect the classification of bank distress in counties. While misreporting could affect the exact number of banks experiencing distress, it is unlikely that errors will completely miss all reports from distressed areas.
} 
as inventor's address and co-inventors, assignee name and patent technology class, are not practical for our setting. First, one of our key interests is measuring the potential migration of independent inventors into firms and across geographic space. Hence, we cannot use the address or assignee name to link inventors across patents. Second, since $90 \%$ of patents filed in the first half of the century are singleinventor patents, co-inventor networks also provide limited variation for matching. Finally, important technological advancements in the 1920s and the 1930s might create biased matches if we use technology classification in the linking process. We overcome this linking challenge in two steps.

In the first step, we match inventors in patents filed from 1905-1949 to the complete count U.S. Census $(1910,1920,1930$, or 1940) that is the closest to their patent filing year (e.g., 1905-1914 to 1910 Census). Similar to Akcigit et al. (2017), we use inventor names and county of residence on the patent text to match to individuals in Census, and filter duplicate matches based on middle initials and age (individuals from 17 to 66 years old in the Census). To increase the potential rate of matching, we introduce two additional steps: a) perform 12 different rounds of matching from most to least precise - with exact matching in the first round to partial name matching in later rounds; and b) create an "inventor-like-job" filter to identify likely inventors in duplicate matches. For example, there could be two possible census records for "Thomas Edison"- one is a laborer, and the other is an inventor. The inventor census record is most likely to be the correct Edison.

The detailed process of matching and the full set of matching statistics can be found in Online Appendix B.19 At each stage, we discard non-unique matches. We performed an extensive examination of the matched data to determine that matches in rounds 1 through 9 provide high-quality matches on the order of accuracy of 85-95\%, while rounds 10-12 did not offer improvements. Hence, we only consider matches in rounds 1-9 in all further analyses. Overall, we are able to match at least $65 \%$ of inventors to each Census. At the strictest round of matching that resembles that in Akcigit et al. (2017), we uniquely match $45 \%$ of inventors, which is similar to the $39 \%$ match rate in Akcigit et al. (2017). The additional rounds of matches as well as the new filtering method bring the percent of unique matches to about $65 \%$. Following much of the literature, we examine whether inventors matched to the Censuses indeed look like inventors, as compared to the general population, and resemble characteristics identified in prior matching efforts. Similar to prior work in Akcigit et al. (2017) and Sarada et al. (2019), we find that inventors tend to be older, male, and married. We also find that the inventors tend to be much more

\footnotetext{
${ }^{19}$ Online Appendix B is available on Tania Babina's website
} 
highly educated and earn much more than an average person, which is similar to Akcigit et al. (2017). Intuitively, we find that inventors have a different distribution of occupations than the general population (this is true whether we limit to the sample of inventors not filtered by occupation or not). For example, inventors are 3 to 4 times more likely to be managers, and 3 to 4 times less likely to be farmers. For brevity, we only report the distribution of occupations for inventors vs. non-inventors for the 1930 Census matched sample in Figure A.6, but all statistics for each decade are available in Online Appendix B.

In the second step, we longitudinally link uniquely-matched inventor-Census individuals to three other Censuses (e.g., inventors matched to 1910 Census are then matched to 1920, 1930, and 1940 Censuses using time-invariant individual-level information in 1910 and other Censuses). We follow leading work on linking individuals across Censuses (e.g., Long and Ferrie 2013) by matching individuals based on their year and place of birth, which are both well-populated in all Censuses of interest. We match between 25 to $55 \%$ of records, depending on how far apart Censuses are, which are similar rates to those in prior research efforts. Online Appendix B provides a detailed description of the methodology and the statistics on match rates for each decade-pair. These two steps produce a longitudinal sample of patenting individuals across four decades, allowing us to track inventors across different organizations of innovation and geographic space.

\subsection{Descriptive Analysis}

The comprehensive nature of our patent data allows us to provide some key descriptive evidence on the population of patents by the two key innovation-producing groups in the first half of the 20th century: independent and firm patents. This descriptive evidence builds on prior pioneering studies (e.g., Lamoreaux and Sokoloff, 1999, Nicholas, 2010) that examine the differences between firm and independent patents using subsamples of patents over 1830-1930 20 Our extended sample allows us to characterize those differences for the 1930-1949 period. We find a stark decline in independent patents over our key sample period of 1910-1949, consistent with prior work. In particular, the share of independent patents declines from $72 \%$ in 1910 s to $59 \%$ in the 1920 s, $44 \%$ in the $1930 \mathrm{~s}$, and $39 \%$ in the 1940 s.

When it comes to the importance of patents, panel A of Table 2 shows that, on average, independent patents received a similar number of citations both before and after the Great Depression 21 This is

\footnotetext{
${ }^{20}$ For example, Lamoreaux and Sokoloff (1999) draws on 6,600 patents filed in 1870-71, 1890-91 and 1910-1911, and Nicholas (2010) examines a sample of approximately 24,000 patents filed between 1830 and 1930.

${ }^{21}$ The distributions look similar when we adjust the count of citations by the number of citations in each major technology
} 
interesting because both Lamoreaux and Sokoloff (1999) and Nicholas (2010) find that independent patents were more highly-cited than firm patents in samples that include earlier sub-periods not included in our analysis. Independent patents also have similar odds of being cited. When it comes to team patenting, 8\% of independent and 11\% of firm patents filed over 1910-1929 have more than one inventor and both groups had 1.1 inventors per patent on average, which matches the statistics in Nicholas (2010). However, the team-patenting gap increases substantially during the 1930-1949 period where the percent of independent team patenting remains the same, but the percent of firm patents with at least two inventors almost doubles to $17 \%$. Finally, we provide new evidence on the distribution of patents by eight technology classes (outer slices) and the distribution of independent and firm patents within each technology class (inner slices within each outer slice) in panel A of Figure A.5. The figure shows that there is substantial heterogeneity across classes in terms of the share of independent vs. firm patents, which is consistent with Nicholas $(2010)$ who argues that independent inventors tended to specialize in certain technologies. Moreover, the figure also shows that some technologies declined in prominence (e.g., "Performing Operations; Transporting") and some increased in importance (e.g., "Electricity") following the Great Depression, which is consistent with prior literature.

Using inventor characteristics obtained from the Census data, we also document that independent inventors are much more likely to be entrepreneurs as compared to firm inventors, which is, of course, intuitive, suggesting that independent inventors were not only "garage inventors", but also pursued commercialization of their ideas. Online Appendix B shows this to be the case in every decade from 1910-1940. In Figures A.7 and A.8, we also document that, as of the 1930 Census, independent inventors (as compared to inventors producing patents within firms) are: (i) more likely to be female; (ii) are, on average, 2 years older; (iii) $4 \%$ more likely to be immigrants (compared to $16 \%$ of immigrants among firm inventors); and (iv) $5 \%$ less likely to be married (compared to $80 \%$ married firm inventors). The differences in immigration rates are particularly interesting because immigrants tend to be more entrepreneurial currently (see Kerr and Kerr (2020) for review), and our evidence suggests that this was true even a hundred years ago. When it comes to socioeconomic status, our data show that independent and firm inventors are equally likely to own a house, with their house ownership rates equal to $56 \%$, which is $8 \%$ higher than that of an average male (48\% of males own a house). Figures A.9 and A.10 also show that, compared to other males, inventors earn more and own more valuable houses, with more variance class and filing decade. 
in home values and earnings for independent inventors as compared to firm inventors. These patterns also hold in the samples of inventors matched to the 1910, 1920, and 1940 complete-count Censuses.

Aggregating firm and independent patents at the county-decade level, shows that the number of firm and independent patents are highly correlated (correlation of $82 \%$ ). Panel B of Table 2 contains statistics on the distribution of firm and independent patents at the county-decade level data, and shows a wide distribution of patents across U.S. counties - consistent with the idea that innovation activity was far less concentrated than at present. Similarly, Figure A.4 shows the ubiquity of independent inventions across U.S. counties during the 1920s, which supports our arguments that pockets of technological entrepreneurship were wide-spread across the U.S. prior to the 1930s.

\section{The Great Depression and the Quantity of Innovation}

In this section, we examine changes in the quantity of patent filings following the Great Depression across locations produced by independent inventors, firms, and the overall innovative activity. We initially examine the short- and medium-run impact of the shock by focusing on the 1910-1940 period, and later examine the (very) long-run effects by extending the patent data through 1999 .

\subsection{Empirical Strategy}

The key objective of this section is to describe how we identify the impact of the Great Depression on patent filing activity. Specifically, we use a differences-in-differences specification which compares innovation activity across counties that had differential severity of bank distress during the Depression period. To remove the effect of regional business cycles and changes in state-level regulation, all our specifications include state-by-time fixed effects. ${ }^{22}$ We also include county fixed effects to control for time-invariant differences in innovation across counties. Our primary specification is:

$$
\text { Ln }(\text { Innovation })_{c s t}=\alpha_{c}+\gamma_{s t}+\beta \text { BankDistress } s_{c s} \times \text { After } 1929_{t}+X_{c s t}^{\prime} \zeta+\epsilon_{c s t}
$$

\footnotetext{
${ }^{22}$ This approach allows us to net out any aggregate changes in the legal or innovation environment around this period. For instance, Beauchamp (2015) documents a rise in patent litigation in the late 1930s, which may affect the incentive to innovate (e.g. Mezzanotti, 2020, Mezzanotti and Simcoe, 2019).
} 
where $c$ denotes a county, $s$ - a state, and $t$ - time (defined in decades if not specified otherwise) $\operatorname{Ln}(\text { Innovation })_{c s t}$ is the natural logarithm of either number of patents, total future patent citations, or average citations per patent ${ }^{24} \alpha_{c}$ are county fixed effects; $\gamma_{s t}$ are state-time fixed effects; BankDistress $s_{c s}$ denotes the degree of bank distress in county $c$ in state $s$ during the Great Depression and equals 1 if the county had at least one bank suspended over 1930-1933, and 0 otherwise; After $1929_{t}$ equals 1 for observations starting in 1930, and 0 otherwise. $X_{c s t}$ includes county-specific controls discussed later; these controls are usually measured before the time of the Great Depression and interacted with the post-dummy, After $1929_{t}$. The estimate of the effect of local bank distress on innovation is given by $\beta$, which measures the differences in patenting in counties with higher bank distress compared to counties with lower bank distress. We cluster standard errors by county, which is the level of our treatment (Bertrand et al. 2004).

There are several potential threats to identification. One issue may be reverse causality. In particular, it could be that the weakness of the innovative sector led to bank failure, and not vice-versa. To understand whether this is a valid concern, it is important to examine the causes of bank distress during the Depression. To the extent that failures were driven by panics rather than weakness in the fundamentals (e.g. Friedman and Schwartz, 1963), reverse causality may not be a concern. However, if distress is driven by a deterioration of the demand for certain technologies, then reverse causality could be a more serious concern. That concern may be fairly minor though in our setting. For instance, Calomiris and Mason (2003) find that lagged liabilities of failed companies do not explain bank failures. Furthermore, this hypothesis is likely to be even less plausible for the innovative sector, which had minimal exposure to banks' loans. In this context, Nanda and Nicholas (2014) argue that publicly traded R\&D firms - which are likely the R\&D firms with a higher share of assets funded by bank loans - only accounted for a minimal share of banks' outstanding loans. Moreover, some of our robustness tests provide further evidence against this concern.

Alternatively, the presence of omitted variable bias is a serious concern in this analysis since bank

\footnotetext{
${ }^{23}$ The higher level of aggregation, as compared to annual, allows us to reduce noise due to some counties not having patents filed each year. As we show later, we find consistent results with 5 or 10 years of aggregation and our findings are not influenced by counties with zero patents (about $10 \%$ of observations in the decennial panel), suggesting robustness to the particular aggregation choice.

${ }^{24} \mathrm{As}$ is standard practice, we add one to the number of patents before taking logs in order to avoid dropping counties without any patents over a given period. This data transformation turns out to be unimportant for our results because about $90 \%$ of counties have at least one patent filed each decade. As detailed later on, the results are not sensitive to different transformations of the dependent variables nor to a particular treatment of counties without patents in a given decade.
} 
distress was clearly not randomly assigned. While it will not be possible to present one single test that can rule out this hypothesis, we present a battery of analyses to help assuage concerns along this dimension.

\subsection{Results and Robustness}

In Table 3 , we show initial evidence that county-level variation in exposure to the financial crisis, proxied by bank suspensions, is associated with a reduction in the quantity of total patenting (column 3), driven by a decline in independent patents (column 1) and no change in firm patenting (column 2). We focus on the significant result for the independent innovation and revisit firm innovation later in the paper. Our estimates suggest that counties that experienced bank distress saw a drop in independent patenting around the Depression that was $13 \%$ higher than counties in the same state without bank distress. This effect does not depend on the way we measure bank distress. Indeed, Table A.1 shows that the results hold using alternative measures. For instance, the effects are consistent when splitting the sample at the median of distress - measured as the share of deposits at suspended banks - or defined as distressed counties that are not in the bottom tercile in terms of distress.

By the same token, we also show in Table A.2 that our findings are unchanged if we conduct alternative transformations of the innovation outcomes. One, relatively minor concern in our setting is related to the presence of zeros in the data, which led us to add a unit to the traditional log-transformation. In column 2, we construct the outcome without adding the unit, therefore dropping the zero observations and focusing on a purely intensive margin. We find that our estimates are very similar to the main one (reported in column 1), and the drop in sample size is only about $10 \%$. We also provide two alternatives to our approach. First, our preferred alternative is to use the inverse hyperbolic sine transformation, which provides a smoother transformation around zero and still allows a similar interpretation of the results (column 3). Second, we also check our results adding a smaller base (0.5) to our outcome (column 4). In both cases, we find almost identical results to our baseline. Furthermore, in column 5, we use the same transformation as in the rest of the paper, but include as part of independent patents also those patents that are assigned to a firm whose name contains the inventors' last or first name (i.g., eponymous firm names, which are likely founded by the inventors or their family members). This test examines whether there might have been some relabeling from independent to firm patents by inventors-entrepreneur in more distressed areas. We find exactly the same estimate when we only include independent patents, suggesting that the relabeling is an unlikely mechanism to explain the decline in independent patents. 
Lastly, Table A.3 shows that the regions with bank distress have substantial reductions in independent patenting even weighting our regression by the size of the county in 192025

However, before we can causally interpret the results in this direction, we need to provide more evidence that can help us to rule out confounding factors discussed earlier. To start, we examine the dynamics of the effects using a longer panel (1900-1950) organized over five-year windows. If our results are explained by an omitted variable that is unrelated to bank distress, we might expect to find differential innovation patterns also before the Depression. In other words, we should find that high distress counties were already experiencing different trends in innovation activities before the shock. Figure 4 provides evidence that is inconsistent with this concern. In general, we find that until the 1930s counties that experienced distress during the Depression did not differ in their relative trends in independent inventors' activity. This changed sharply during the 1930-1934 period when we document a sudden reduction in innovation activity by technology entrepreneurs in the more severely affected areas.

Given the lack of differential trends, the main remaining concern for our analysis is that bank distress at the county level may be correlated with some other shock that was contemporaneous to the Depression that was correlated with local economic distress and innovation (but not through economic distress). One possibility is that bank distress could capture heterogeneity in demand for technologies across counties, which in turn may affect the production of technologies in the area. To the extent that this shift in demand happens roughly at the same time as the Depression or as a result of it, its effect may be undetectable in the pre-trend analysis. Regarding this concern, there are a few important things to consider. First, from a theoretical standpoint, a demand-side explanation would require that, in some way, the decision of an inventor to develop a technology is influenced by the demand for that technology in the local area. However, this hypothesis goes against a large body of work in economic history (e.g., Lamoreaux and Sokoloff 2001b), which has shown that the market for technology during this period was either national or - at the very least - regional. Therefore, variation in demand should not be captured in our analysis, particularly after the inclusion of state-by-time fixed effects.

Second, to the extent that firms and technology entrepreneurs produce a similar type of innovation, a demand explanation would also predict a decline in firm innovation in distress areas. However, as we show in Table 3 , we find that bank distress does not seem to predict any short-run changes in

\footnotetext{
${ }^{25}$ As discussed more later, we also find that our results are robust to the exclusion of patents without any citations (Table A.8). In other words, the decline is not simply driven by inventors who stopped producing patents of absolutely no value.
} 
aggregate patenting by firms at the county level. This firm-level result helps more broadly to address other alternative explanations, which would generally predict a similar response between firm and independent inventors. For instance, one special case is the reverse causality hypothesis discussed earlier. If the decline in banks was caused by the reduction in innovation and not vice-versa, the contraction should also be observed in firms. If anything, the effect on firms should be larger, since banks and firms are more likely to be connected through direct lending relationships.

These arguments suggest that demand-side explanations are unlikely drivers of our results. However, we also want to provide further direct evidence against this hypothesis. In general, if local demand shocks are important to explain our results, we should also expect to find a null result for technologies in which local demand is likely not important. To examine this issue, in Table 4 we reshape our data at countyby-time-by-technology class level. ${ }^{26}$ Since it is hard to categorize ex-ante which technology is more likely to be affected by local demand, we take two approaches that do not require any ex-ante categorization. To start, we augment our main specification by including technology-by-time fixed effects. To the extent that demand explains our results and this is heterogeneous across technologies, we should expect our main effect to go away. Instead, we find that the result with this new set of fixed effects is still large and significant (column 2) and not different from the estimates at this level of aggregation without any of these additional fixed effects (column 1). As a second test, we repeat the main specification separately for each of the top five largest independent inventor technology classes, as measured by the number of independent patents filed in the 1920s. Across all five, we find sizable, significant and similar results (columns 3 to 7 ).

While these results provide strong evidence against the role of demand for technologies in explaining our results, there is still a potential concern that the response to the Depression may in part reflect other differences across distressed and non-distressed areas that might lead to differential trends in innovation following the Great Depression. To visualize this idea, in the first panel of Figure 3 we plot the estimated differences in county-level characteristics between areas with and without bank distress during the Depression. This analysis is conducted adjusting for differences across states by including state fixed effects 27 On average, we find that counties experiencing bank distress are significantly different than areas

\footnotetext{
${ }^{26}$ In particular, these technology classes are human necessities, performing operations or transporting, fixed constructions, mechanical engineering, lighting, heating, weapons, blasting engines or pumps, and physics.

${ }^{27}$ The analysis reports the betas and the $95 \%$ confidence intervals for the coefficients that are estimated running a simple regression of the reported outcomes, which are standardized to mean of 0 and standard deviation of 1 to make variables more comparable (i.e. z-score), on an indicator variable for the counties with bank distress, while also controlling for state
} 
that did not experience bank failures. For instance, our treated areas tend to produce more patenting and have more banks in the 1920s. Not surprisingly, the areas that experienced bank distress also end up with higher unemployment in $1937{ }^{28}$ However, most of these differences between treatment and control are really explained by the fact that counties experiencing distress are on average larger than counties that did not experience distress. Consistent with this hypothesis, in the second panel of Figure 3 , we repeat the same analysis as before now also controlling for the log of population in the county in 1920 . Strikingly, this extra control absorbs a significant portion of the variation in county-level characteristics between those with and without bank distress. In particular, we no longer find any significant differences across county characteristics. Also, as we show in Figure A.4, while there is certainly some geographic concentrations in bank distress in the early 1930s and patenting activity in the 1920s, much of that variation is explained by state-level variation and differences in county population-both of which are absorbed with our fine fixed effects.

In light of this evidence, in Table 5, we examine empirically whether our findings could be explained by observable differences in pre-shock characteristics that might send those counties on differential innovation trends following the Great Depression. In column 1, we show that the results go through once we also control for the size of the population in 1920 interacted with a post-1929 dummy. Similarly, the results are robust to controlling for a measure of the size of the banking sector at the county level (column 2).

Building on this idea, we present two additional tests. First, in column 3, we control for the importance of manufacturing in 1929 and, again, find that it does not significantly affect our results. Second, we control for two variables that should, in part, also capture the negative effect of the Great Depression, but do not directly proxy for the health of the local financial system. We control for the unemployment rate in 1937 in column 4, and the change in county-level sales between 1929-1933 in column 5. The logic behind this test is simple: an omitted variable would be a concern only if this variable is correlated with the level of bank distress in the local area and also drives the results. In general, the same factors that may have been correlated with one dimension of the Great Depression - bank failure - may be also be correlated with other dimensions, such as the contraction in retail sales or unemployment rates. Therefore, controlling for these alternative proxies for the depth of the Depression can help to gauge the extent to which our result may be capturing other economic forces. However, it is also important to fixed effects.

${ }^{28}$ We use 1937 because county-level unemployment data was not available for 1929-1933. 
keep in mind that these variables may also be endogenously driven by bank distress, and, therefore, may partially capture the impact of bank failure and the overall funding shocks in which we are interested. We find that the addition of these controls does not significantly affect our estimates, providing reassuring evidence for our analysis. Furthermore, the results also hold when we add all control variables together (column 6). Lastly, our results are also robust to controlling for the importance of New Deal funding, therefore, suggesting that this government intervention_- which likely favored incumbent firms - does not appear to explain our results (Table A.4) ${ }^{29}$

As an alternative way to deal with the heterogeneity between treatment and control, we also implement a matching estimator using a nearest-neighbor matching approach. This approach allows us to deal with concerns about non-linear effects of co-variates acting as possible confounds. In particular, we start by considering all counties that did not experience distress during the Depression. For each of these counties, we check whether we can find any other county that experienced bank distress, where the following conditions also hold: (a) the county is in the same state; (b) population is within a $25 \%$ bandwidth around the unaffected county; (c) independent' innovation in the pre-period (the 1920s) is similar 30 Since we only analyze counties that are selected using these criteria, the sample of counties in this analysis is only about a third of the original sample, but, on average, counties in treatment and control groups are much more homogeneous. In Table A.5, we re-estimate our main specification using this matched sample for independent patents (columns 1 and 2) and firm patents (columns 3 and 4). Overall, we replicate our key findings, in terms of economic and statistical significance: negative effects on independent patenting and a failure to reject no effect on firm patenting.

\subsection{Wealth Shocks and Independent Inventors}

Altogether, the findings suggest that local economic distress from the Great Depression was an important force explaining some of the decline in independent inventions in the aftermath of this crisis. However, banks may matter for technological entrepreneurs for different reasons. While including or excluding

\footnotetext{
${ }^{29}$ We follow Fishback et al. (2006) and proxy for the size of New Deal by measuring the total amount of relief grants in a given county. The data on relief grants come from Fishback et al. (2003). Using this raw data, we construct two proxies. First, in columns 1 and 2, we control for the amount of relief funds divided by the population in 1920. Second, in columns 3 and 4 , we control for the absolute size of the relief grants (log-transformed). In both cases, we find little difference in our inference.

${ }^{30}$ We divide counties into three groups: (a) no independent innovation (zero patents before); (b) moderate independent innovation (between zero and fifty patents); (c) high independent innovation (above fifty patents). We then use this definition to match counties.
} 
all possible mechanisms is outside the scope of this paper, we can provide evidence that may shed light on the plausibility of some channels. One hypothesis is that bank shocks were linked to a reduction in the wealth of local investors, therefore limiting their ability or willingness to fund risky projects. This idea is consistent with most of the literature on the history of early-stage technological innovation in the pre-Depression era as well as inline with the novel stylized facts presented in Section 2, If this is an important channel to explain our result, then we should find comparable results even using proxies for shocks to local wealth.

Indeed, we find that the drop in independent inventions can be observed using a wealth local shock measure. In particular, we identify counties experiencing variation in agricultural land values using heterogeneity in the exposure to the 1920 farming crisis, as discussed in Rajan and Ramcharan (2015). In Rajan and Ramcharan (2015), the authors argue that the boom in the U.S. agricultural sector in the late 1910s - which was a consequence of the disruption in European and Russian food production due to WWI and a sharp increase in the U.S. world exports - led to a large decline in real estate values in the 1920s. Banks loaded with loans underwritten to finance the boom were particularly vulnerable during the Great Depression (Jaremski and Wheelock, 2018). Following these papers, we construct a county-level measure of exposure to the farming shock by looking at the increase in revenue that is induced by the changes in prices in global commodity markets (Haines et al., 2010) 31

To start, we validate this measure relative to the previous literature: we show that counties that experienced a larger farming boom during 1917-1920 also experienced higher bank distress during the Depression (in column 1 of Table 6). In line with the discussion in Jaremski and Wheelock (2018), this result confirms that the shock to real estate in the 1920s explains part of the weakness of American banks at the onset of the Depression. Then we replicate the same differences-in-differences model presented previously, but now using this alternative treatment in Table 6. Columns 2 and 3 show that the results are consistent with those using bank distress as a treatment: the boom-driven increase in the farmland prices predicts a reduction in patenting by independent inventors following the beginning of the Depression. ${ }^{32}$

\footnotetext{
${ }^{31}$ To be specific, our treatment is the county-level change from 1917 to 1920 in the international commodity price index calculated for each county, where weights are the crop share of a given farm product out of total county farm output and prices are international farm product prices, as in Rajan and Ramcharan (2015).

${ }^{32}$ It is important to be clear that agricultural land price shocks are not being used as an instrumental variable for bank distress, but rather both bank distress and agricultural land price shocks are likely to be different measures associated with wealth shocks to available local capital for financing technological entrepreneurs. Direct systematic measures of the wealth of these investors is difficult to obtain, but, as we showed previously, local investors in technological ventures were also often holders of substantial local real estate, making this a plausible proxy for a substantial portion of investors' wealth.
} 
Importantly, our results are similar even when adjusting for differences in size by controlling for the population in 1920 (Table A.11). Overall, these findings provide some suggestive evidence about the importance of wealth shocks in explaining the contraction in independent inventors documented before. Furthermore, this result helps address reverse causality concerns mentioned earlier, since we exploit variation determined long before the Great Depression.

\subsection{The Effects over the Long-run}

The evidence presented so far has confirmed that bank distress during the Great Depression predicted an economically large contraction in patenting activity by independent inventors. Before moving forward, it is important to understand to what extent this effect was temporary or persistent. This question is particularly important given the context of these results. As Figure 4 shows, the aggregate decline in independent inventors was not a transient phenomenon. While our results confirm that the shock caused by the Depression was a significant factor in triggering this decline, this does not necessarily imply that the effect of our main shock persisted in the long-run.

To examine this question, we repeat our main analyses using a sample that covers patenting activity by independent inventors up to 1999. One important caveat in this type of analysis is that we are not going to be able to prove that the Depression caused a long-term decline in independent patenting. Instead, we can simply make a statement about whether the short-term effects of the banking shock persisted over time. Despite this limitation, which is common in these types of studies, understanding whether the decline persisted is still important, since it may help in clarifying whether the effect of the Depression may still explain a large share of changes in the innovation ecosystem decades later.

We turn to the data with this limitation in mind. In the pre-trend analysis (Figure 4), we have already shown that the contraction in independent inventor patenting occurred not only in the 1930s, but also persisted in the 1940s. In Table 7, we extend this analysis further. In particular, using data at the county-by-decade level, we separately estimate a parameter of bank distress for the 1930s that captures short-term response, and then, on top of that, for the 1940-1990 decades, which captures long-term responses. The estimate in column 1 suggests that counties that experienced bank distress during the Great Depression appears to be characterized by persistently lower patenting by independent inventors long after the Depression.

In fact, in Figure 5, we re-run our primary specification using a much longer panel, covering patents 
filed between 1890 and 1999. We find that the county-level bank distress from the Great Depression has no relationship with changes in independent patenting in the decades prior to the $1930 \mathrm{~s}$, but it is associated with a sudden decline in independent patenting in the 1930s, which persisted in every decade for the next 70 years. Therefore, even if distress from the Great Depression were only a catalyst for changes already on the horizon, this lack of "catching-up" by distressed counties suggests that the shock had important distributional effects. This evidence is consistent with the idea that large shocks can lead to equilibria shift in the organization of innovation: the reduction in activity by technology entrepreneurs may have led to a dissolution of other important aspects of the local ecosystems, such as funding networks or patents agents, that help facilitate the innovation process (Lamoreaux et al., 2006) leading to hysteresis. Such an ecosystem can exist as an equilibrium, but also devolve into equilibria where patenting moves into firms when faced with disruptions to entrepreneurial activity Aghion and Tirole 1994, Gromb and Scharfstein 2002, Hellmann 2007). For example, while many regions in the U.S. would love to develop into Silicon Valley, perhaps not surprisingly, moving to an equilibrium where the local environment supports that sort of technological entrepreneurial activity is not trivial (Kerr and Robert-Nicoud, 2020).

\section{The Great Depression and the Innovation Ecosystem}

\subsection{Discussion}

So far, we have shown that the Great Depression was followed by a contraction of innovation by independent inventors. Importantly, these effects are persistent over time. There are several ways to interpret this evidence. On the one hand, this result may be consistent with the idea that the financial contraction brought about by the Depression negatively affected the level of dynamism in the economy. In fact, our tests show that the financing contraction led to a sizable reduction in innovation activity that is undertaken outside of firm boundaries. In turn, this may suggest the presence of a "missing generation" of highly productive entrants (Gourio et al., 2016).

On the other hand, a reduction in the amount of innovation that is undertaken by technology entrepreneurs does not necessarily imply a reduction in the overall dynamism of the economy. First, the long-run implications of the shock not only depend on its quantity effect, but also on the quality adjustment that this may generate. As discussed by Caballero et al. (1994), a negative shock may also represent an economic opportunity to the extent that this event also triggers cleansing dynamics in the economy. 
Second, the actual impact of the shock for the economy also depends on the ability of innovation to shift across different types of organizations. Altogether, a crisis period may also be an opportunity to reshape innovation efforts towards more efficient organizational forms and impactful projects (Manso et al., 2019).

In order to explore these dimensions, we increase the breadth of our analysis to the overall ecosystem of innovation at the local level. In particular, we present three sets of tests to help us understand the economic interpretation of our initial findings. First, we examine whether the decline in the quantity of innovation was also accompanied by a decrease in the overall quality of local innovation. Studying innovation quality in this context is particularly interesting because the quality of historic patents can be evaluated based on their long-run influence on future generations of innovations through citations. Second, we examine whether the drop in the quantity of independent innovation also led to a decrease in overall local innovation activity, looking more closely at the role played by firms during this period. In this setting, our longitudinally-matched inventor data allow us to examine individual inventor migration across organizational forms of innovation. Third, we examine whether the shock led to a reduction in the stock of human capital in distressed areas.

\subsection{Results and Robustness}

In Table 8, we examine potential changes in the quality of innovation by using our previously employed differences-in-differences design. In particular, we look at the total number of future citations received by patents filed in each county-decade as the outcome of interest (columns 1 and 2). In stark contrast to our quantity results, we find essentially no differential changes in the future citations given to independent inventor patents that are filed in more distressed counties (column 1). The same holds for the sample of all U.S.patents: firm plus independent (column 2). We can also see this result in Figure A.11, which replicates the design of Figure 4 , but takes total citations given to independent inventions as the dependent variable. As before, we find no evidence of pre-trends, but this time we also do not find any changes after the shock.

How do we reconcile these findings of no changes in the number of future citations with the previous finding of a large drop in the number of patents filed in the same counties? In columns 3 and 4 of Table 8, we show that the divergent results are driven by a significant increase in the average quality of patents filed. As can be seen in Figure A.12, the average citations per independent patent rise suddenly in 1930-1934 in counties that experience more severe economic distress, despite no evidence of differential 
trends prior to the Depression. In particular, based on Table 8 , in distressed counties average citations increase by about $13 \%$ more than non-distressed counties in the same state.

This evidence - combined with the decline in the quantity of innovation - potentially suggests that the drop in patenting by independent inventors might be driven by lower-quality projects that are no longer patented. Therefore, while technology entrepreneurs were forced to reduce their activity in response to the shock, inventors with high-quality technologies were still able to succeed in the marketplace. Consistent with this hypothesis, we find that the drop in the quantity of patents is driven by a drop in the number of low-citation patents, rather than a relative increase in highly-cited patents. In Table 9. we split patents based on the number of citations within the same cohort period (1910-1940) and technology class. In particular, we split patents into those that belong to the top $1 \%$ and the bottom $99 \%$ by the number of future citations, as well as top and bottom $10 \% / 90 \%$ and $25 \% / 75 \%$. We then count the number of patents in each group at the county-decade level and log-transform these dependent variables. Across these groups, we consistently find that the decline is mostly explained by a decrease in the number of patents that are of lower quality, while highly-cited patents remain roughly constant ${ }^{33}$ Therefore, while technology entrepreneurs were forced to reduce their activity in response to the shock, inventors with high-quality technologies were still able to produce their inventions. More broadly, this is consistent with the evidence in Babina (2020) who find that valuable entrepreneurial ideas get funded even in recessions. Importantly, this pattern is not simply driven by the decline in patents that are characterized by extremely low quality, such as those inventors engaged in patenting purely for personal enjoyment/non-pecuniary benefits. In Appendix Table A.8, we show this by replicating our result showing the decline in independent patenting by using only patents that have received at least one citation.

Taken all together, we find that the average quality of innovation increases during the Depression, as inventors become less likely to patent lower-quality ideas. This result on the increased average quality is robust along several important dimensions. First, following the previous discussion on alternative ways to measure the wealth shock, we replicate these findings using the land value shock discussed in the previous section (Table A.10). Second, controlling for county size does not significantly change the results (Table

\footnotetext{
${ }^{33}$ As we make the definition of high-quality broader (i.e., top 25\%), we tend to find some effect in that group. However, even under that definition, the effect is much larger (roughly double in size) in the lower quality category. Furthermore, these results are presented controlling for population consistent with the robustness tests in the rest of the analyses. It is important to point out that our findings also hold without this control-we find a larger effect for lower quality patents. However, without the control, the effect is also significant for the top patents, suggesting that, at the margin, high-quality patents may have also suffered, though this bank distress driven decline cannot be separated from the differential trends in larger and smaller counties.
} 
A.6). Third, the results are unchanged when we adjust citations following Hall et al. (2001) and absorb variation in citation patterns across technologies (column 1 of Table A.7) ${ }^{34}$ Finally, we find consistent results using average citations without log-transforming it as an outcome (column 2 of Table A.7).

In the second set of our analysis, we find that, in contrast to technological entrepreneurs, the aggregate local innovation activity by firms did not seem to be impaired, as shown in column 2 of Table 3 . If anything, patenting by firms actually increases relatively more in distressed areas over the longer-run, as shown in column 2 of Table $7^{35}$ Despite the limitations of analyses that look at long-term responses, this evidence may suggest that the shock leads to some substitution in the production of innovation between independent inventors and firms. While evidence on the increase in the quality of firm patents in the short-run is limited ${ }^{36}$ we do find more consistent evidence of the increased quality of firm patents in the long-run (coefficient on "BankDistress X After1939" in column 2 of Table A.12).

To understand what can explain this shift in the quality of firm patents at the county-level, we turn to our longitudinal individual inventor-level data to examine whether there are any changes in the probability that, in distressed regions, pre-shock independent inventors work for firms in the post-Depression period. To run this test, we restrict the sample to the subset of inventors who: a) are found in the 1920 Census, b) patent as independents prior to the Great Depression (i.e., decades of the 1910s and the 1920s); and c) have at least one patent in the $1930 \mathrm{~s}{ }^{37}$ Using this cross-section, we test whether independent inventors within a state were more likely to patent within firms if they lived in counties that experienced high bank distress. ${ }^{38}$ With this test, we want to understand whether financial distress associated with the Depression predicted a reallocation of inventors into firms. In Table 10, we show that independent inventors operating in high-distress areas were more likely to patent within firms in the following decade

\footnotetext{
${ }^{34}$ In particular, we scale citations by the average number of citations in each major CPC technology class over the window of time considered in the analysis (1910-1940).

${ }^{35}$ Interestingly, we also do not find any changes in the distribution of high- vs. low-quality patents for firms (Table A.9).

${ }^{36}$ See, for example, the marginally insignificant coefficient on "BankDistress X After1929" that measures changes in total citations given to firm patents filed in the 1930s, as compared to those in 1910-1929 in column 2 of Table A.12.

${ }^{37}$ To assign the inventor's location during the Depression, we use the location in the 1930 Census and, when this is not available, the location in the 1920 Census. We condition on inventors matched to the 1920 Census, since this Census year is used to construct controls.

${ }^{38}$ For this analysis, we use a dummy version of the treatment, that splits the sample distribution at the median. Our main county-level results also work using a consistent split at the median (Table A.1). We switch to the median because the previous version of the treatment (bank distress equals one when there is some distress event) does not have enough variation using individual-level data, as more than $90 \%$ of the sample resides in the distressed areas. Indeed, in unreported analysis, we find that the individual- level analysis using the main treatment definition produces results that are close to zero. However, negative effects for individual-level results occur for any reasonable alternative measure of the treatment that generates a more meaningful variation in the treatment that provides sufficient power. For instance, in Table A.13, we obtain similar and consistent results when we use a continuous bank distress treatment (columns 2 and 4 ).
} 
(column 1), and this holds also when we add county-level controls (column 2) and individual- and countylevel controls (column 3) ${ }^{39}$ The consistency of results across all specifications is suggestive of the effects likely being primarily driven by changes in the local market support for innovation, rather than its direct impact on individual productivity (Bernstein et al. 2017) 40

To bolster our interpretation of these findings, we present two robustness tests. First, in Table A.13 we repeat the same analysis using a sub-sample of inventors who are less likely to be matched to wrong individuals in the Census datasets (columns 3 and 4) ${ }^{41}$ Despite a significant decrease in sample size, the result remains significant and qualitatively consistent with our main effects. If anything, the magnitude of the coefficients increases, as we would expect in response to a reduction of measurement error in this sample. Second, in Table A.14, we conduct a placebo analysis by examining whether independent inventors in distressed counties also moved into firms more often before the 1930s. In columns 1 and 2, we examine a sample of independent inventors that were active in the 1910s and check whether they were more likely to move into firms in the 1920s if they were in counties that experienced more distress during the Great Depression, and in columns 3 and 4, we repeat the same analysis focusing on the 1900s inventors moving into firms in the 1910s. Across all these analyses, we consistently find no evidence of a differential likelihood to move into a firm prior to the 1930s.

This cross-organizational migration is consistent with the more muted observed response of the countylevel quantity of firm patents filed to bank distress: innovative workers are re-allocated from more to less external-finance dependent firms in affected areas. Going back to our original county-level data in Table 6. we show long-run reductions in independent patenting in these distressed counties - the reductions lasting till the present day. By contrast, firm patenting in distressed counties appears to see a resurgence in the long-run, compensating for the long-run decline in independent patenting. Overall, the movement of inventors across organizational forms might explain why the aggregate county-level firm patenting appears to have been somewhat insulated from bank distress, despite the declines observed for some

\footnotetext{
${ }^{39}$ In terms of individual-level controls, we control for an inventor's (log of) age, sex, status of self-employment status, and home ownership. At the county-level, we control for log-population in 1920.

${ }^{40}$ Bernstein et al. (2017) examine the partial equilibrium effects of economic distress on the productivity of inventoremployees and found a decline in the innovation of employees exposed to housing shocks.

${ }^{41}$ We thank Nicolas Ziebarth for suggesting this robustness test. We only consider inventors if their patent (to be matched to Census) was applied for within a two-year window around the Census year (two year before or two year after). This filter increases the likelihood that the inventor is not matched to a wrong person in Census because that inventor moved across county lines 5 to 3 years apart from Census and there is another person living in that county with the same name. We think this approach decreases the probability of false positives, but we also feel confident that our full sample is likely of a sufficient quality to undertake our inference.
} 
more affected firms in Nanda and Nicholas (2014).

An alternative mechanism is that the shock may have affected the local economy in part because of a reduction in the local availability of human capital. This would have been the case if inventors responded to the shock by moving outside of distressed counties. Indeed, the recent literature in economic history highlights the importance of migration to understand the effect of the Depression in the American economy (Feigenbaum 2015). Since we matched our inventor data to the Censuses, we can use location data provided by the Censuses to test this hypothesis ${ }^{42}$ In particular, we construct a dummy variable for mobility equal to one if an inventor is located in 1940 in a different county than in 192043 In Table 11. we show that data are not consistent with this hypothesis: we find no evidence that inventors were more keen to migrate out of highly distressed areas. In unreported results, we find that this fact is true for both inventors working for firms and independently. This result suggests that the shock — while it affected the way innovation was organized - did not significantly impact the stock of human capital in the area, at least in the short run 44 This is a surprising finding, given some evidence of relatively high mobility among inventors in this time period (Akcigit et al. 2017 and Sarada et al. 2019). However, the null result of distress on inventor geographic mobility coupled with the increased mobility of independent inventors into firms suggests that obtaining paid employment was preferable to bearing the costs of geographic reallocation.

\section{Conclusion}

Using a differences-in-differences design comparing counties that were more exposed to bank distress during the Great Depression to counties less affected, we document the important role of the Great Depression in triggering a large reduction in the quantity of patents filed by the largest group of innovators of that period-independent inventors. However, this sudden and persistent decline in the activity of technology entrepreneurs is only one side of the story. First, despite the decline in the quantity of patents

\footnotetext{
${ }^{42}$ To run this test, we use all inventors (either firm or independent) that patented in the 1920s, and we do not impose any condition on the post-Depression patenting, since we can follow their geographic movement using the Census datasets. This lighter filter explains why this sample is much larger than the one used for the previous analysis on cross-organization migration, which requires inventors to patent following the Depression.

${ }^{43}$ The analysis covers all individuals that were active inventors (either in firms or as independents) in 1920. Since we use the location as defined in the Census, we also require that the person has been listed in the 1920 and 1940 Censuses with a known county.

${ }^{44}$ Migration in these regions by inventors could have risen after 1940, but this is the last date at which we have full count censuses that allow us to observe individual-level migration patterns.
} 
filed, we find no measurable negative effects on the overall impact of surviving patents, because the shock did not affect high-quality innovations on which future generations of inventions are built. Second, the shock on its own did not affect firms negatively. If anything, firms seem to have benefited in the long-run, in part because of a reallocation of inventors into firms. Third, the shock did not reduce the amount of human capital in the area, because inventors did not leave the distressed areas in response to the shock.

This evidence on the Great Depression can be thought of as a cautionary tale when examining the impact of shocks on innovative activity. Our findings highlight that, to truly understand the impact of the shock, it is crucial to examine the effect on the overall innovation ecosystem. In general, sufficiently large shocks to financing - on top of having a direct effect on one group of innovators - can also lead to a reallocation across more and less affected organizational forms. At the same time, to the extent that the shock actually induces a cleansing effect (Caballero et al., 1994), the overall effect on technological progress could be substantially lower, or might even be positive.

These results are particularly useful in the context of the contemporaneous debate regarding a reduction in dynamism in the economy. For instance, these results are consistent with Guzman and Stern (2016) and Babina et al. (2019) who highlight the importance of adjusting for the quality of start-ups and the quality of their human capital in order to study dynamism. Clearly, our results, which cover a different historical period, cannot directly speak to whether dynamism declined following the Great Recession. However, as it is said, history may not repeat, but it often rhymes. For example, while the Financial Crisis caused a large and persistent drop in newly-created firms, the aftermath saw incredible technological advances coming from incumbents and startups alike. These included the births of fintech, cloud storage/computing, and the sharing economy, as well as significant advances in artificial intelligence (AI) that drove a boom in AI investments (Babina et al. 2020) - all consistent with the broad patterns we observe following the Great Depression. Our finding of a surprising resilience of the highest impact innovations, even in the face of one of the largest exoduses of technological entrepreneurship in the U.S. history in the aftermath of the Great Depression, is certainly suggestive that dynamism may also be more resilient in the face of distress than it may appear at first glance. Our findings suggest that accounting for redistribution, especially cross-organizationally, is likely to be critical in understanding the overall effects on innovation and growth in the aftermath of an economic crisis. 


\section{References}

Aghion, P., Bloom, N., Blundell, R., Griffith, R., Howitt, P., 2005. Competition and innovation: An inverted-u relationship. The quarterly journal of economics 120, 701-728.

Aghion, P., Tirole, J., 1994. The management of innovation. The Quarterly Journal of Economics 109, $1185-1209$.

Akcigit, U., Grigsby, J., Nicholas, T., 2017. The Rise of American Ingenuity: Innovation and Inventors of the Golden Age. Working Paper 23047, National Bureau of Economic Research.

Akkoyun, H. C., 2018. Investor protection and financing innovation: Evidence from blue sky laws .

Andrews, M., 2019. Comparing historical patent datasets. Available at SSRN 3415318 .

Ante, S. E., 2008. Creative capital: Georges Doriot and the birth of venture capital. Harvard Business Press.

Babina, T., 2020. Destructive creation at work: How financial distress spurs entrepreneurship. The Review of Financial Studies 33, 4061-4101.

Babina, T., Fedyk, A., He, A. X., Hodson, J., 2020. Artificial intelligence, firm growth, and industry concentration. Firm Growth, and Industry Concentration (July 14, 2020) .

Babina, T., Garcia, D., Tate, G. A., 2017. Friends during hard times: evidence from the great depression. Columbia Business School Research Paper .

Babina, T., Ma, W., Moser, C., Ouimet, P., Zarutskie, R., 2019. Pay, employment, and dynamics of young firms. Employment, and Dynamics of Young Firms (July 23, 2019) .

Bai, J., Carvalho, D., Phillips, G. M., 2018. The impact of bank credit on labor reallocation and aggregate industry productivity. The Journal of Finance 73, 2787-2836.

Bassetto, M., Cagetti, M., De Nardi, M., 2015. Credit crunches and credit allocation in a model of entrepreneurship. Review of Economic Dynamics 18, 53-76.

Beauchamp, C., 2015. The first patent litigation explosion. Yale LJ 125, 848.

Bell, A., Chetty, R., Jaravel, X., Petkova, N., Van Reenen, J., 2019. Who becomes an inventor in america? the importance of exposure to innovation. The Quarterly Journal of Economics 134, 647-713.

Benmelech, E., Frydman, C., Papanikolaou, D., 2017. Financial Frictions and Employment during the Great Depression. Tech. rep., National Bureau of Economic Research.

Berkes, E., 2016. Comprehensive Universe of U.S. Patents (CUSP): Data and Facts. Working Paper.

Bernanke, B. S., 1983. Nonmonetary Effects of the Financial Crisis in the Propagation of the Great Depression. The American Economic Review 73, 257-276.

Bernstein, S., Giroud, X., Townsend, R. R., 2016. The impact of venture capital monitoring. The Journal of Finance 71, 1591-1622.

Bernstein, S., McQuade, T., Townsend, R. R., 2017. Do household wealth shocks affect productivity? evidence from innovative workers during the great recession. Tech. rep., National Bureau of Economic Research. 
Bertrand, M., Duflo, E., Mullainathan, S., 2004. How Much Should We Trust Differences-In-Differences Estimates? The Quarterly Journal of Economics 119, 249-275.

Caballero, R. J., Hammour, M. L., others, 1994. The Cleansing Effect of Recessions. American Economic Review 84, 1350-1368.

Calomiris, C. W., Mason, J., 1997. Contagion and bank failures during the great depression: The june 1932 chicago banking panic. American Economic Review 87, 863-83.

Calomiris, C. W., Mason, J. R., 2003. Fundamentals, Panics, and Bank Distress During the Depression. American Economic Review 93, 1615-1647.

Cole, H. L., Ohanian, L. E., 2007. A second look at the us great depression from a neoclassical perspective. Great depressions of the twentieth century. Minneapolis: Federal Reserve Bank of Minneapolis pp. 2158.

De Rassenfosse, G., van Pottelsberghe de la Potterie, B., 2013. The role of fees in patent systems: Theory and evidence. Journal of Economic Surveys 27, 696-716.

Duval, R., Hong, G. H., Timmer, Y., 2020. Financial frictions and the great productivity slowdown. The Review of Financial Studies 33, 475-503.

Eichengreen, B., 2004. Understanding the great depression. The Canadian Journal of Economics/Revue canadienne d'Economique 37, 1-27.

Feigenbaum, J. J., 2015. Intergenerational mobility during the great depression .

Field, A. J., 2003. The most technologically progressive decade of the century. American Economic Review 93, 1399-1413.

Fishback, P. V., Horrace, W. C., Kantor, S., 2001. The impact of new deal expenditures on local economic activity: An examination of retail sales, 1929-1939. Tech. rep., National Bureau of Economic Research.

Fishback, P. V., Horrace, W. C., Kantor, S., 2006. The impact of new deal expenditures on mobility during the great depression. Explorations in Economic History 43, 179-222.

Fishback, P. V., Kantor, S., Wallis, J. J., 2003. Can the new deal's three rs be rehabilitated? a programby-program, county-by-county analysis. Explorations in Economic History 40, 278-307.

Fleming, L., Greene, H., Li, G., Marx, M., Yao, D., 2019. Government-funded research increasingly fuels innovation. Science 364, 1139-1141.

Frésard, L., Hoberg, G., Phillips, G. M., 2020. Innovation activities and integration through vertical acquisitions. The Review of Financial Studies 33, 2937-2976.

Friedman, M., Schwartz, A. J., 1963. A Monetary history of the US 1867-1960. Princeton University Press.

Garcia-Macia, D., Hsieh, C.-T., Klenow, P. J., 2019. How destructive is innovation? Econometrica 87, $1507-1541$.

Gompers, P. A., Gornall, W., Kaplan, S. N., Strebulaev, I. A., 2019. How do venture capitalists make decisions? Journal of Financial Economics . 
Gorton, G., Laarits, T., Muir, T., 2019. 1930: First modern crisis. Tech. rep., National Bureau of Economic Research.

Gorton, G., Metrick, A., 2013. The federal reserve and panic prevention: The roles of financial regulation and lender of last resort. Journal of Economic Perspectives 27, 45-64.

Gourio, F., Messer, T., Siemer, M., 2016. Firm Entry and Macroeconomic Dynamics: A State-Level Analysis. American Economic Review 106, 214-218.

Gromb, D., Scharfstein, D., 2002. Entrepreneurship in equilibrium. Tech. rep., National bureau of economic research.

Gross, D. P., Sampat, B. N., 2020. Inventing the endless frontier: The effects of the world war ii research effort on post-war innovation. Harvard Business School Strategy Unit Working Paper .

Guglielmo, M., 1998. What caused chicago bank failures in the great depression? a look at the 1920s. $\mathrm{PhD}$ Thesis .

Guzman, J., Stern, S., 2016. The State of American Entrepreneurship: New Estimates of the Quantity and Quality of Entrepreneurship for 15 US States, 1988-2014. Working Paper 22095, National Bureau of Economic Research.

Haines, M. R., et al., 2010. Historical, demographic, economic, and social data: the united states, 17902002. Ann Arbor, MI: Inter-university Consortium for Political and Social Research .

Hall, B. H., Jaffe, A. B., Trajtenberg, M., 2001. The nber patent citation data file: Lessons, insights and methodological tools. Tech. rep., National Bureau of Economic Research.

Hall, B. H., Lerner, J., 2010. The financing of r\&d and innovation. In: Handbook of the Economics of Innovation, Elsevier, vol. 1, pp. 609-639.

Hall, R. E., 2015. Quantifying the lasting harm to the us economy from the financial crisis. NBER Macroeconomics Annual 29, 71-128.

Haltiwanger, J., Jarmin, R. S., Miranda, J., 2012. Who Creates Jobs? Small versus Large versus Young. The Review of Economics and Statistics 95, 347-361.

Hellmann, T., 2007. When do employees become entrepreneurs? Management science 53, 919-933.

Huber, K., 2018. Disentangling the effects of a banking crisis: evidence from german firms and counties. American Economic Review 108, 868-98.

Hughes, T. P., 2004. American genesis: a century of invention and technological enthusiasm, 1870-1970. University of Chicago Press.

Jacoby, N. H., Saulnier, R. J., 1947. Business finance and banking. In: Business Finance and Banking, NBER, pp. 221-230.

Jaffe, A. B., Trajtenberg, M., Henderson, R., 1993. Geographic localization of knowledge spillovers as evidenced by patent citations. the Quarterly journal of Economics 108, 577-598.

Jaremski, M. S., Wheelock, D. C., 2018. Banking on the Boom, Tripped by the Bust: Banks and the World War I Agricultural Price Shock. Working Paper 25159, National Bureau of Economic Research. 
Kelly, B., Papanikolaou, D., Seru, A., Taddy, M., 2018. Measuring technological innovation over the long run. Tech. rep., National Bureau of Economic Research.

Kenney, M., 2011. How venture capital became a component of the us national system of innovation. Industrial and Corporate Change 20, 1677-1723.

Kerr, S. P., Kerr, W. R., 2020. Immigration policy levers for us innovation and startups. Tech. rep., National Bureau of Economic Research.

Kerr, W. R., Lerner, J., Schoar, A., 2011. The consequences of entrepreneurial finance: Evidence from angel financings. The Review of Financial Studies 27, 20-55.

Kerr, W. R., Lincoln, W. F., 2010. The supply side of innovation: H-1b visa reforms and us ethnic invention. Journal of Labor Economics 28, 473-508.

Kerr, W. R., Robert-Nicoud, F., 2020. Tech clusters. Journal of Economic Perspectives 34, 50-76.

Lamoreaux, N. R., Levenstein, M., Sokoloff, K. L., 2006. Mobilizing venture capital during the second industrial revolution: Cleveland, ohio, 1870-1920. Capitalism and Society 1.

Lamoreaux, N. R., Sokoloff, K. L., 1999. Inventors, firms, and the market for technology in the late nineteenth and early twentieth centuries. In: Learning by doing in markets, firms, and countries, University of Chicago Press, pp. 19-60.

Lamoreaux, N. R., Sokoloff, K. L., 2001a. Market trade in patents and the rise of a class of specialized inventors in the 19th-century united states. American Economic Review 91, 39-44.

Lamoreaux, N. R., Sokoloff, K. L., 2001b. Market Trade in Patents and the Rise of a Class of Specialized Inventors in the 19th-Century United States. American Economic Review 91, 39-44.

Lamoreaux, N. R., Sokoloff, K. L., 2005. The Decline of the Independent Inventor: A Schumpterian Story? Working Paper 11654, National Bureau of Economic Research.

Lamoreaux, N. R., Sokoloff, K. L., Sutthiphisal, D., 2009. The Reorganization of Inventive Activity in the United States during the Early Twentieth Century. Working Paper 15440, National Bureau of Economic Research.

Landes, D. S., Mokyr, J., Baumol, W. J., 2012. The invention of enterprise: Entrepreneurship from ancient Mesopotamia to modern times. Princeton University Press.

Lee, J., Mezzanotti, F., 2017. Bank Distress and Manufacturing: Evidence from the Great Depression. Tech. rep.

Li, G.-C., Lai, R., D’Amour, A., Doolin, D. M., Sun, Y., Torvik, V. I., Amy, Z. Y., Fleming, L., 2014. Disambiguation and co-authorship networks of the us patent inventor database (1975-2010). Research Policy 43, 941-955.

Long, J., Ferrie, J., 2013. Intergenerational occupational mobility in great britain and the united states since 1850. American Economic Review 103, 1109-37.

Luttmer, E. G. J., 2012. Technology diffusion and growth. Journal of Economic Theory 147, 602-622.

Manso, G., Balsmeier, B., Fleming, L., 2019. Heterogeneous innovation and the antifragile economy . 
Margo, R. A., 1993. Employment and unemployment in the 1930s. Journal of Economic Perspectives 7, $41-59$.

Mezzanotti, F., 2020. Roadblock to innovation: The role of patent litigation in corporate r\&d. Management Science .

Mezzanotti, F., Simcoe, T., 2019. Patent policy and american innovation after ebay: An empirical examination. Research Policy 48, 1271-1281.

Mitchener, K., Richardson, G., 2019. Network contagion and interbank amplification during the great depression. Journal of Political Economy 127.

Mitchener, K., Wheelock, D., 2013. Does the structure of banking matter for economic growth? evidence from u.s. state banking markets. Explorations in Economic History 50, 161-178.

Moreira, S., 2016. Firm dynamics, persistent effects of entry conditions, and business cycles. Persistent Effects of Entry Conditions, and Business Cycles (October 1, 2016) .

Moretti, E., 2019. The effect of high-tech clusters on the productivity of top inventors. Tech. rep., National Bureau of Economic Research.

Moretti, E., Steinwender, C., Van Reenen, J., 2019. The intellectual spoils of war? defense r\&d, productivity and international spillovers. Tech. rep., National Bureau of Economic Research.

Moser, P., 2005. How do patent laws influence innovation? evidence from nineteenth-century world's fairs. American economic review 95, 1214-1236.

Moser, P., Voena, A., Waldinger, F., 2014. German jewish émigrés and us invention. American Economic Review 104, 3222-55.

Mowery, D., Rosenberg, N., 1989. Technology and the Pursuit of Economic Growth.

Nanda, R., Nicholas, T., 2014. Did bank distress stifle innovation during the Great Depression? Journal of Financial Economics 114, 273-292.

Nicholas, T., 2008. Does innovation cause stock market runups? evidence from the great crash. American Economic Review 98, 1370-96.

Nicholas, T., 2010. The role of independent invention in US technological development, 1880-1930. The Journal of Economic History 70, 57-82.

Postel-Vinay, N., 2016. What caused chicago bank failures in the great depression? a look at the 1920s. Journal of Economic History 76, 478-519.

Rajan, R., Ramcharan, R., 2015. The Anatomy of a Credit Crisis: The Boom and Bust in Farm Land Prices in the United States in the 1920s. American Economic Review 105, 1439-1477.

Richardson, G., 2007. Categories and causes of bank distress during the great depression, 1929-1933: The illiquidity versus insolvency debate revisited. Explorations in Economic History 44, 588-607.

Richardson, G., Troost, W., 2009. Monetary intervention mitigated banking panics during the great depression: quasi-experimental evidence from a federal reserve district border, 1929-1933. Journal of Political Economy 117, 1031-1073. 
Romer, C. D., 1993. The nation in depression. Journal of Economic Perspectives 7, 19-39.

Sarada, S., Andrews, M. J., Ziebarth, N. L., 2019. Changes in the demographics of american inventors, 1870-1940. Explorations in Economic History 74, 101275.

Schumpeter, J. A., 1934. Depressions. Can We Learn from Past Experience.

Schumpeter, J. A., 1942. Capitalism, socialism, and democracy.

Seru, A., 2014. Firm boundaries matter: Evidence from conglomerates and r\&d activity. Journal of Financial Economics 111, 381-405.

Shane, S., 2008. Fool's Gold?: The truth behind angel investing in America. Oxford University Press.

Siemer, M., 2016. Firm entry and employment dynamics in the great recession. Available at SSRN 2172594

Teece David, J., 1988. Technological change and the nature of the firm. Giovanni Dosi .

Temin, P., et al., 1976. Did monetary forces cause the Great Depression? Norton.

Ziebarth, N., 2013. Identifying the Effects of Bank Failures from a Natural Experiment in Mississippi during the Great Depression. American Economic Journal: Macroeconomics 5, 81-101. 
Figure 1: Patents Filed by Technology Class

The figure shows the annual number of patents filed by patent technology class. The technology classes correspond to the highest level of Cooperative Patent Classification (CPC) classifications by the U.S. Patent and Trademark Office (USPTO). The sample is the universe of all patents granted by the USPTO to U.S. inventors or firms.

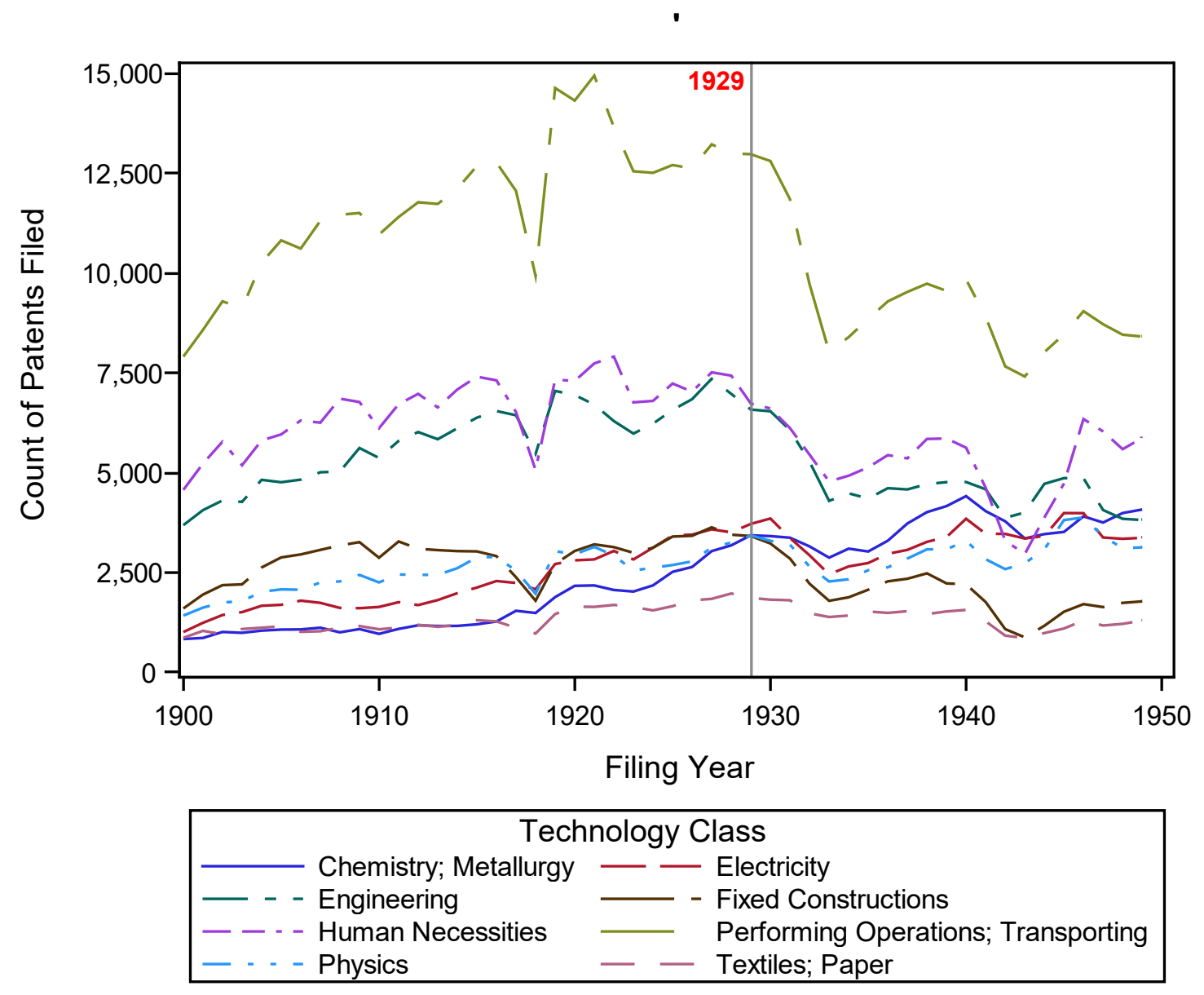


Figure 2: Aggregate Number of Patents by Patent Type

The figure shows the annual number of patents filed by patent type. The sample is the universe of all patents granted by the U.S. Patent and Trademark Office (USPTO). "Independent" are patents by inventors residing in the U.S. that were either unassigned or assigned to individuals at the time of the patent grant date. "Firm" are patents that were assigned to a U.S. company at the time of the patent grant date.

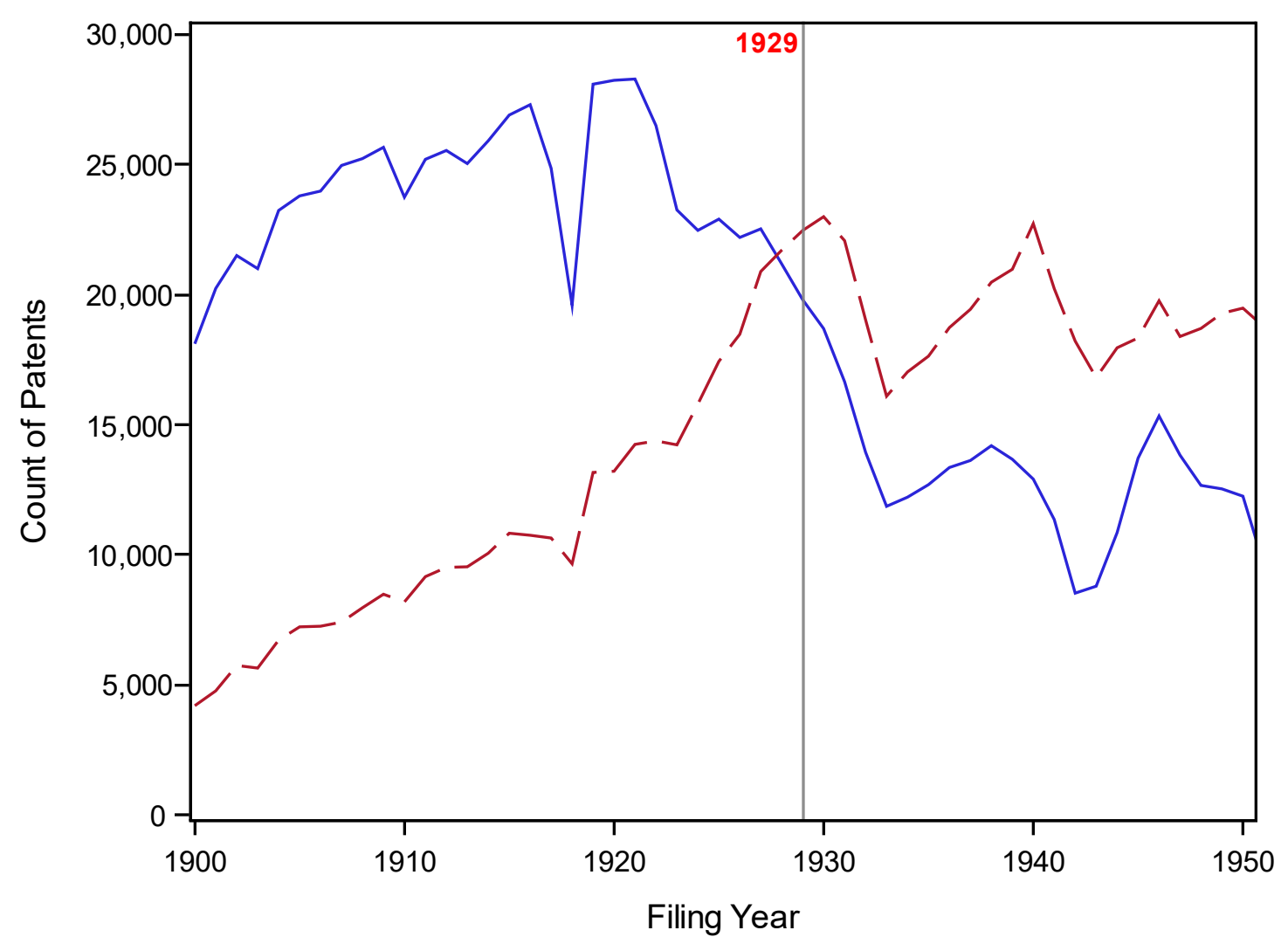

Patent Category $\longrightarrow$ Independent -- Firm 
Figure 3: Covariates Across Counties With and Without Bank Distress

The figures report the balance of covariates across two specifications: (1) controlling for state fixed-effects in sub-figure (a); (2) controlling for both state fixed-effect and (log) population in 1920 sub-figure (b). Specifically, the figures report the plot of the coefficients from a regression where our main treatment variable - dummy equal to one for a county with bank distress during the Great Depression - is regressed on the variable reported in the legend. Each variable is standardized to mean of 0 and standard deviation of 1 (i.e., z-score) to facilitate the comparison between variables. For patent count variables, we also apply a log transformation, consistent with the analyses in the main tables. Coefficient estimates and 95\% confidence interval are displayed as well. Independent are patents by inventors residing in the U.S. that were either unassigned or assigned to individuals at the time of the patent grant date.

(a) Difference within-state

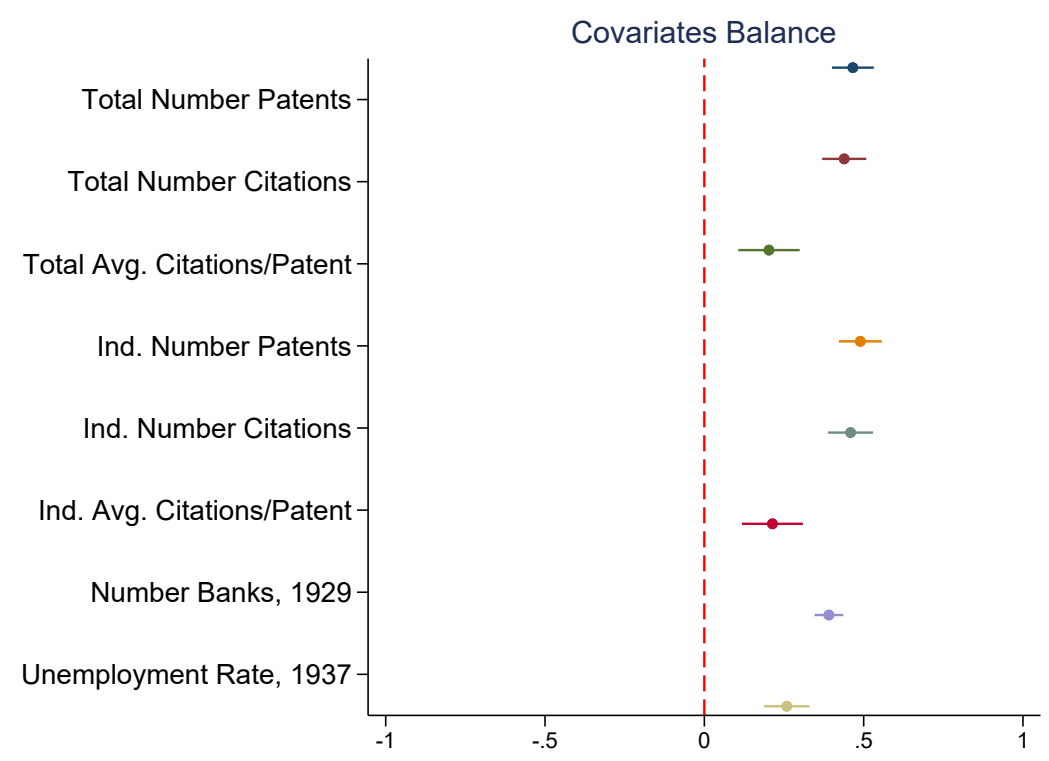

(b) Difference within-state and adjusting for population

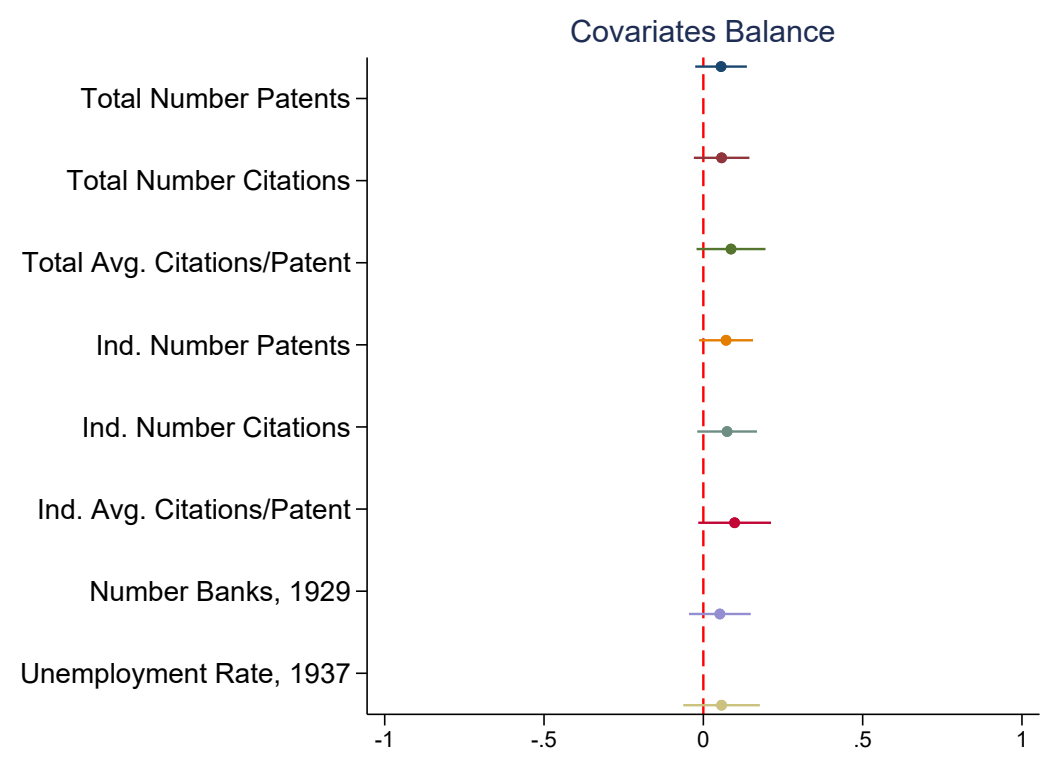


Figure 4: Bank Distress During the Great Depression and Independent Innovation Quantity

The figure shows estimates from a differences-in-differences regression of the number of independent patents on bank distress during the Great Depression. The estimation strategy relies on cross-sectional variation in bank distress across U.S. counties within a state. The sample is the near universe of all independent patents granted by the U.S. Patent and Trademark Office (USPTO). Independents are patents by inventors residing in the U.S. that were either unassigned or assigned to individuals at the time of the patent grant date. The unit of observation is county-time, where time is five years. The dependent variable is the logarithm of one plus the number of independent patents filed over five-year periods within each county. Bank Distress is an indicator variable equal to 1 for counties with at least one bank suspension during the Great Depression years of 1930 through 1933, inclusive. The estimates of the effect of bank distress on independent innovations are the coefficients on the interaction between Bank Distress and five-year indicators that measure the relative change in patenting in areas with high bank distress relative to the reference period of 1925-1929. Specifically, we plot betas and $95 \%$ confidence intervals from a differences-in-differences regression:

$$
\text { Ln }(\text { NumberPatents }+1)_{c s t}=\alpha_{c}+\gamma_{s t}+\sum \beta_{t} 1_{t} \text { BankDistress } s_{c s}+\epsilon_{c s t}
$$

where $c$ denotes county, $s$-state, and $t$ - five-year period. $\alpha_{c}$ is county fixed effects; $\gamma_{s t}$ is state-time fixed effects; five-year indicators equal 1 for a given time period (e.g., 1900-04), and 0 otherwise. Standard errors are clustered at the county level.

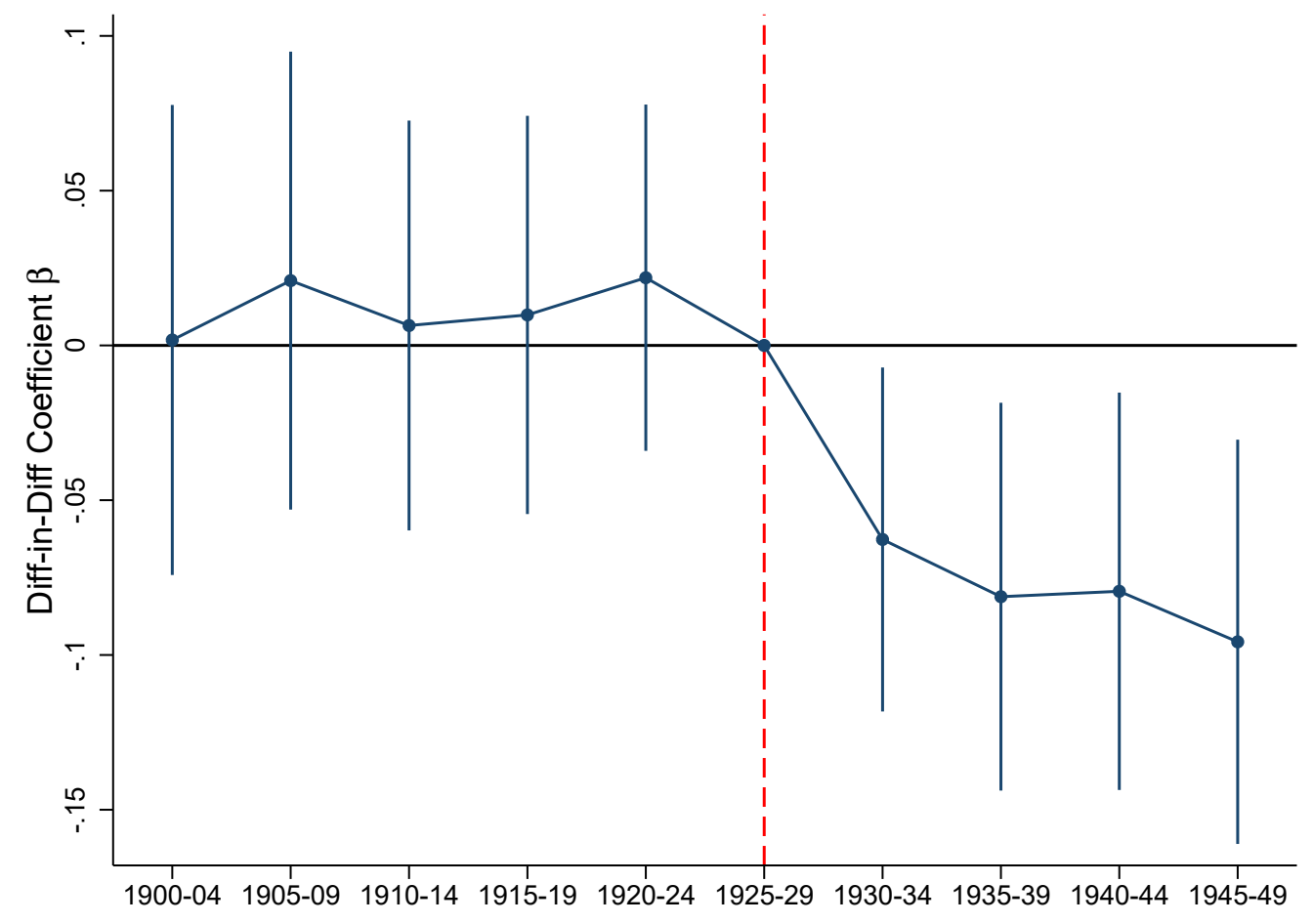


Figure 5: Bank Distress During the Great Depression and Long-Run Independent Patenting

The figure shows estimates from a differences-in-differences regression of the number of independent patents on bank distress during the Great Depression looking over more than a century from 1890 to 1999. The estimation strategy relies on cross-sectional variation in bank distress across U.S. counties within a state. The sample is the near universe of all independent patents granted by the U.S. Patent and Trademark Office (USPTO). Independent are patents by inventors residing in the U.S. that were either unassigned or assigned to individuals at the time of the patent grant date. The unit of observation is county-time, where time is a decade. The dependent variable is the logarithm of one plus the number of independent patents filed over ten-year periods within each county. Bank Distress is an indicator variable equal to 1 for counties with at least one bank suspension during the Great Depression years of 1930 through 1933, inclusive. The estimates of the effect of bank distress on independent innovations are the coefficients on the interaction between Bank Distress and five-year indicators that measure the relative change in patenting in areas with high bank distress relative to the reference period of 1920-1929. Specifically, we plot betas and 95\% confidence intervals from a differences-in-differences regression:

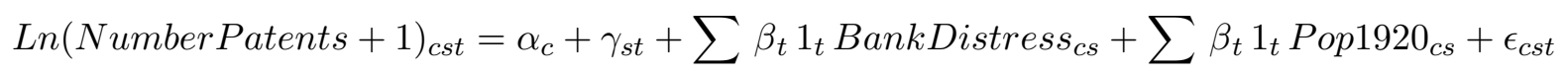

where $c$ denotes county, $s$-state, and $t$-decade; $\alpha_{c}$ is county fixed effects; $\gamma_{s t}$ is state-time fixed effects; ten-year indicators equal 1 for a given time period (e.g., 1890-1899), and 0 otherwise; Pop1920 is the natural logarithm of a county's population in the 1920s. Standard errors are clustered at the county level.

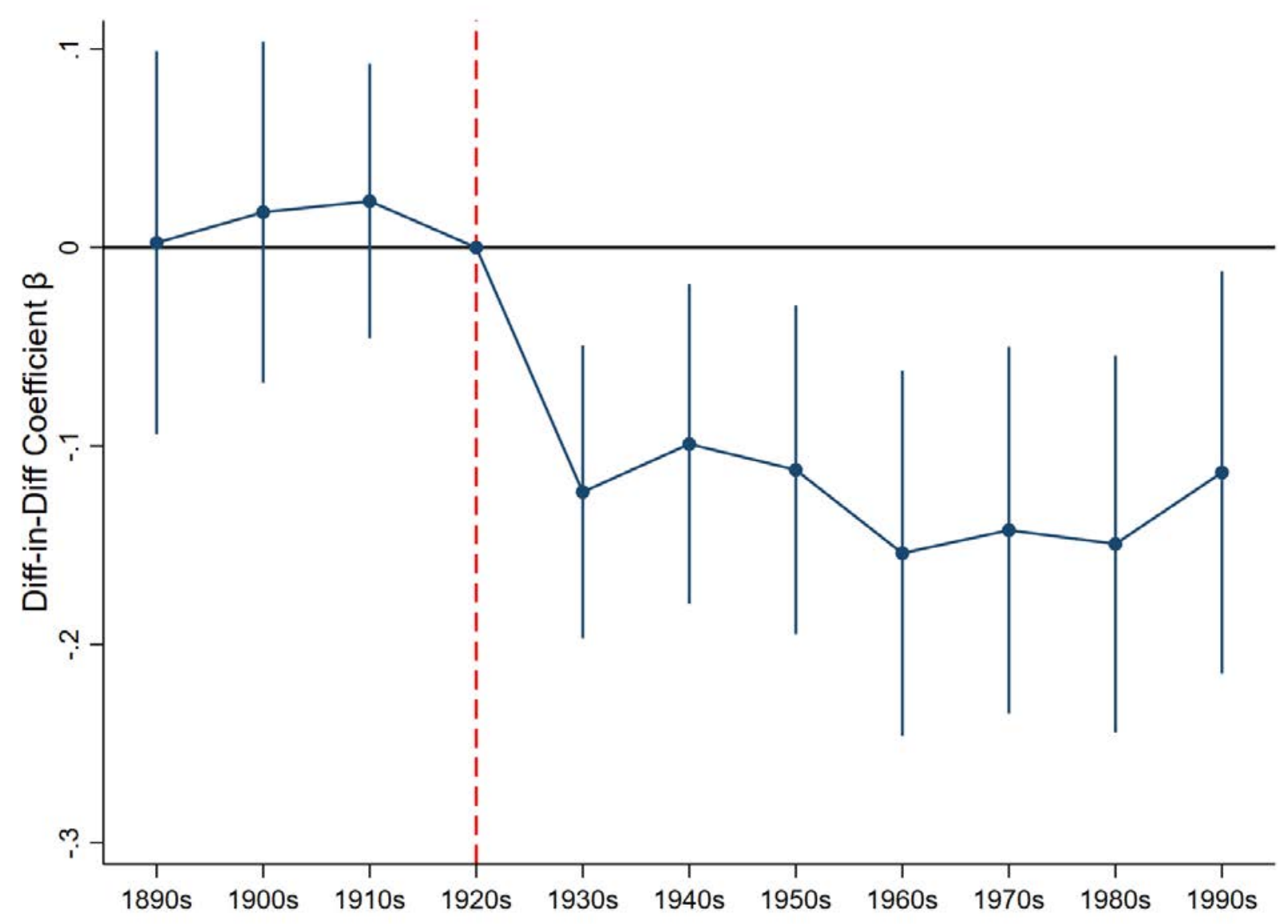


Table 1: County-Level Summary Statistics for All and for Distressed Counties

The table shows summary statistics across all counties and only counties distressed during the Great Depression - counties with at least one bank suspension over 1930-1933 (Bank Distress equals one). For patent count variables, we also apply a log transformation, consistent with the analyses in the main tables. Bank Distress \% is calculated as the cumulative number of bank suspensions from 1930 through 1933 as a share of total banks in 1929. Independent are patents by inventors residing in the U.S. that were either unassigned or assigned to individuals at the time of the patent grant date. Firm are patents that were assigned to a U.S. company at the time of the patent grant date.

\begin{tabular}{|c|c|c|c|c|c|c|}
\hline & \multicolumn{3}{|c|}{ All Counties } & \multicolumn{3}{|c|}{ Counties w/Suspensions } \\
\hline & Mean & Std.Dev. & NumObs & Mean & Std.Dev. & NumObs \\
\hline \multicolumn{7}{|c|}{$1920 s$ Patenting per county (log): } \\
\hline Number Patents & 2.72 & 1.63 & 2975 & 3.04 & 1.62 & 2129 \\
\hline Number Citations & 3.24 & 1.96 & 2975 & 3.60 & 1.92 & 2129 \\
\hline Average Citations/Patent & 1.00 & 0.47 & 2975 & 1.04 & 0.41 & 2129 \\
\hline \multicolumn{7}{|l|}{ Independent: } \\
\hline Number Patents & 2.60 & 1.50 & 2975 & 2.90 & 1.48 & 2129 \\
\hline Number Citations & 3.10 & 1.84 & 2975 & 3.45 & 1.79 & 2129 \\
\hline Average Citations/Patent & 0.99 & 0.48 & 2975 & 1.03 & 0.42 & 2129 \\
\hline \multicolumn{7}{|l|}{ US Firms: } \\
\hline Number Patents & 1.05 & 1.65 & 2975 & 1.25 & 1.78 & 2129 \\
\hline Number Citations & 1.29 & 2.01 & 2975 & 1.52 & 2.15 & 2129 \\
\hline Average Citations/Patent & 0.49 & 0.66 & 2975 & 0.56 & 0.67 & 2129 \\
\hline \multicolumn{7}{|c|}{ Banking County-level Variables: } \\
\hline Bank Distress & 0.72 & 0.45 & 2975 & 1.00 & 0.00 & 2129 \\
\hline Bank Distress \% & 0.30 & 0.28 & 2975 & 0.42 & 0.24 & 2129 \\
\hline Number Banks, 1929 & 8.12 & 10.28 & 2975 & 9.88 & 11.54 & 2129 \\
\hline \multicolumn{7}{|c|}{ Misc. County-level Variables: } \\
\hline Population, $1920(\log )$ & 9.81 & 0.98 & 2948 & 9.99 & 0.94 & 2116 \\
\hline CngCommPrice, 1917-1920 & 3.58 & 2.51 & 2829 & 3.90 & 2.58 & 2055 \\
\hline Cng Agric. Debt, 1910-1920 & 2.89 & 0.74 & 2418 & 2.80 & 0.70 & 1798 \\
\hline Unemployment Rate, 1937 & 0.01 & 0.01 & 2973 & 0.01 & 0.01 & 2127 \\
\hline Value Crops, $1910(\log )$ & 14.09 & 1.06 & 2812 & 14.29 & 0.95 & 2051 \\
\hline Chg Retail Sales, 1929-1933 & -0.48 & 0.23 & 2941 & -0.49 & 0.21 & 2105 \\
\hline
\end{tabular}


Table 2: Summary Statistics for Independent Inventor and Firm Patents

The table shows summary statistics across independent inventor patents and patents assigned to firms. Independent are patents by inventors residing in the U.S. that were either unassigned or assigned to individuals at the time of the patent grant date. Firm are patents that were assigned to a U.S. company at the time of the patent grant date. Panel A shows statistics for patent-level data, and Panel B-for county-decade level data. Each panel shows statistics for patents filed during 20 years before and 20 years since the start of the Great Depression. For county-level data, Number Patents refers to total number of patents within each county-decade; Number Citations is the sum of citations given to patents filed within each county-decade; Independent Average Citations is calculated as number of county-decade citations divided by the number of county-decade patents (it is set to zero when there are no patents).

\begin{tabular}{|c|c|c|c|c|c|c|c|c|}
\hline & $\begin{array}{l}\text { Number of } \\
\text { Observations }\end{array}$ & Mean & $\begin{array}{l}\text { Std } \\
\text { Dev }\end{array}$ & $\begin{array}{l}50 \text { th } \\
\text { Pctl }\end{array}$ & $\begin{array}{l}\text { 75th } \\
\text { Pctl }\end{array}$ & $\begin{array}{l}\text { 90th } \\
\text { Pctl }\end{array}$ & $\begin{array}{l}\text { 95th } \\
\text { Pctl }\end{array}$ & $\begin{array}{l}\text { 99th } \\
\text { Pctl }\end{array}$ \\
\hline \multicolumn{9}{|l|}{ Panel A: Patent-level Data } \\
\hline \multicolumn{9}{|l|}{ Patents filed in 1910-1929 } \\
\hline Independent Number Citations & 469,000 & 2.1 & 4.1 & 1 & 3 & 6 & 8 & 16 \\
\hline Firm Number Citations & 251,000 & 2.1 & 3.8 & 1 & 3 & 6 & 8 & 16 \\
\hline \multicolumn{9}{|l|}{ Patents filed in 1930-1949 } \\
\hline Independent Number Citations & 246,000 & 5.4 & 7.7 & 3 & 7 & 12 & 17 & 31 \\
\hline Firm Number Citations & 343,000 & 5.7 & 7.7 & 4 & 7 & 13 & 18 & 33 \\
\hline \multicolumn{9}{|c|}{ Panel B: County-decade-level Data } \\
\hline \multicolumn{9}{|l|}{ Patents filed in 1910-1929 } \\
\hline Independent Number Patents & 5,950 & 78.8 & 546 & 13 & 34 & 99.5 & 217 & 1245 \\
\hline Firm Number Patents & 5,950 & 42.2 & 381 & 0 & 3 & 25.5 & 92 & 885 \\
\hline Independent Number Citations & 5,950 & 166 & 1,286 & 21 & 59 & 196 & 441 & 2,689 \\
\hline Firm Number Citations & 5,950 & 90.2 & 831 & 0 & 5 & 50.5 & 193 & 2,063 \\
\hline Independent Average Citations & 5,950 & 1.7 & 1.4 & 1.5 & 2.2 & 3 & 3.6 & 6.1 \\
\hline Firm Average Citations & 5,950 & 0.9 & 2.3 & 0 & 1.4 & 2.7 & 3.7 & 7 \\
\hline \multicolumn{9}{|l|}{ Patents filed in 1930-1949 } \\
\hline Independent Number Patents & 5,950 & 41.3 & 304 & 4 & 13 & 46 & 107 & 715 \\
\hline Firm Number Patents & 5,950 & 57.6 & 420 & 1 & 5 & 39 & 147 & 1,435 \\
\hline Independent Number Citations & 5,950 & 224 & 1,752 & 17 & 62 & 241 & 556 & 3,928 \\
\hline Firm Number Citations & 5,950 & 329 & 2,389 & 0 & 26 & 219 & 784 & 8,269 \\
\hline Independent Average Citations & 5,950 & 3.9 & 3.6 & 3.8 & 5.5 & 7.3 & 9 & 14.4 \\
\hline Firm Average Citations & 5,950 & 2.9 & 4.4 & 0 & 5 & 7.6 & 10 & 20 \\
\hline
\end{tabular}


Table 3: Bank Distress During the Great Depression and Innovation Quantity

The table shows estimates from a differences-in-differences regression of the number of patents by patent type on bank distress during the Great Depression. The estimation strategy relies on cross-sectional variation in bank distress across U.S. counties within a state. The sample is the near universe of all patents granted by the U.S. Patent and Trademark Office (USPTO) to either U.S. inventors or U.S. firms. The unit of observation is county-decade, for the period 1910-1940. In column 1, we limit the sample to independent patents and define the dependent variable as the logarithm of one plus the number of independent patents filed over ten-year periods within each county. Independent are patents by inventors residing in the U.S. that were either unassigned or assigned to individuals at the time of the patent grant date. In column 2, we limit the sample to patents assigned to U.S. firms and define the dependent variable as the logarithm of one plus the number of U.S. firm patents filed over ten-year periods within each county. Firm patents are those that were assigned to a U.S. company at the time of the patent grant date. In column 3, the dependent variable is the logarithm of one plus the number of all U.S. patents filed over ten-year periods within each county. Bank Distress is an indicator variable equal to 1 for counties with at least one bank suspension during the Great Depression years of 1930 through 1933, inclusive. The estimates of the effect of bank distress on patents are the coefficients on the interaction between Bank Distress and the After1929 indicator, which equals one for the observations starting from the 1930s decade. Standard errors are clustered at the county level. *, **, and $* * *$ indicate significance at the $10 \%, 5 \%$, and $1 \%$ levels, respectively.

\begin{tabular}{lccc}
\hline & $(1)$ & $(2)$ & $(3)$ \\
& Ln(\# Ind. Patents+1) & Ln(\# Firm Patents+1) & Ln(\# Total Patents+1) \\
\hline BankDistress X After1929 & $-0.127^{* * *}$ & 0.016 & $-0.105^{* * *}$ \\
& $(-4.47)$ & $(0.60)$ & $(-3.42)$ \\
\hline StateXTime FE & Y & Y & Y \\
County FE & Y & Y & Y \\
Start Decade & 1910 & 1910 & 1910 \\
End Decade & 1940 & 1940 & 1940 \\
Adj R-Sq & 0.895 & 0.896 & 0.903 \\
Obs & 11,900 & 11,900 & 11,900 \\
\hline
\end{tabular}


Table 4: Bank Distress During the Great Depression and Independent Innovation Across Technology Classes

The table shows estimates from a differences-in-differences regression of the number of independent patents across technology classes on bank distress during the Great Depression. The estimation strategy relies on cross-sectional variation in bank distress across U.S. counties within a state. The sample is the near universe of all independent patents granted by the U.S. Patent and Trademark Office (USPTO). Independent are patents by inventors residing in the U.S. that were either unassigned or assigned to individuals at the time of the patent grant date. The unit of observation is county-decade-technology class in columns 1 and 2, and county-decade in columns 3 through 7, for the period 1910-1940. In columns 1 through 7, the dependent variable is the logarithm of one plus the number of independent patents. In columns 1 and 2, we count patents within each county-decade-technology class. In columns 3 through 7 , we limit the sample to 5 most frequent patented technology classes by independent inventors in the 1920s: column 3 - human necessities (CPC class A); column 4 - performing operations or transporting (CPC class B); column 5 - fixed constructions (CPC class E); column 6 - mechanical engineering, lighting, heating, weapons, blasting engines or pumps (CPC class F); column 7 - physics (CPC class G). Bank Distress is an indicator variable equal to 1 for counties with at least one bank suspension during the Great Depression years of 1930 through 1933, inclusive. The estimates of the effect of bank distress on patents are the coefficients on the interaction between Bank Distress and the After1929 indicator, which equals one for the observations starting from the 1930s decade and onwards. Standard errors are clustered at the county level. ${ }^{*}, * *$, and $* * *$ indicate significance at the $10 \%, 5 \%$, and $1 \%$ levels, respectively.

\begin{tabular}{lccccccc}
\hline & \multicolumn{7}{c}{ Ln(\# Independent Patents+1) } \\
\cline { 2 - 7 } & $(1)$ & $(2)$ & $(3)$ & $(4)$ & $(5)$ & $(6)$ & $(7)$ \\
\hline BankDistress X After1929 & $-0.140^{* * *}$ & $-0.140^{* * *}$ & $-0.142^{* * *}$ & $-0.156^{* * *}$ & $-0.151^{* * *}$ & $-0.148^{* * *}$ & $-0.101^{* * *}$ \\
& $(-8.78)$ & $(-8.72)$ & $(-5.63)$ & $(-5.79)$ & $(-6.65)$ & $(-6.01)$ & $(-5.30)$ \\
\hline StateXTime FE & $\mathrm{Y}$ & $\mathrm{Y}$ & $\mathrm{Y}$ & $\mathrm{Y}$ & $\mathrm{Y}$ & $\mathrm{Y}$ & $\mathrm{Y}$ \\
County FE & $\mathrm{Y}$ & $\mathrm{Y}$ & $\mathrm{Y}$ & $\mathrm{Y}$ & $\mathrm{Y}$ & $\mathrm{Y}$ & $\mathrm{Y}$ \\
TechnologyXStateXTime FE & $\mathrm{N}$ & $\mathrm{Y}$ & $\mathrm{N}$ & $\mathrm{N}$ & $\mathrm{N}$ & $\mathrm{N}$ & $\mathrm{N}$ \\
Technology & $\mathrm{All}$ & $\mathrm{All}$ & $\mathrm{A}$ & $\mathrm{B}$ & $\mathrm{E}$ & $\mathrm{F}$ & $\mathrm{G}$ \\
Start Decade & 1910 & 1910 & 1910 & 1910 & 1910 & 1910 & 1910 \\
End Decade & 1940 & 1940 & 1940 & 1940 & 1940 & 1940 & 1940 \\
Adj R-Sq & 0.733 & 0.830 & 0.842 & 0.859 & 0.789 & 0.823 & 0.804 \\
Obs & 59,500 & 59,500 & 11,900 & 11,900 & 11,900 & 11,900 & 11,900 \\
\hline
\end{tabular}


Table 5: Bank Distress, Other Economic Shocks, and Independent Innovation during the Great Depression

The table shows that the results on lower independent patenting in high bank distress counties during the Great Depression remain robust to controlling for the potential differential trends due to ex-ante county characteristics or other economic shocks during the Great Depression. The sample is the near universe of independent patents granted by the U.S. Patent and Trademark Office (USPTO) to either U.S. inventors or U.S. firms. Independent are patents by inventors residing in the U.S. that were either unassigned or assigned to individuals at the time of the patent grant date. The unit of observation is county-decade, for the period 1910-1940. In columns 1 through 6, the dependent variable is the logarithm of one plus the number of independent patents filed over ten-year periods within each county. Bank Distress is an indicator variable equal to 1 for counties with at least one bank suspension during the Great Depression years of 1930 through 1933, inclusive. The estimates of the effect of bank distress on patents are the coefficients on the interaction between Bank Distress and After1929 indicator, which equals one for the observations starting from the 1930s decade and onwards. In columns 1 and 2, respectively, we control for the size of counties, as proxied by the logarithm of county's population as of 1920 U.S. Census, and a dummy for counties with less than six banks as of 1929. In column 3, we control for the importance of manufacturing proxied by the share of population in manufacturing over total population (times 100). In columns 4 and 5, we control for the county-level demand shocks to make sure the results are not driven by changes in local demand. Unemployment, 1937 is the county-level unemployment rate during the 1937 recession. Chg Retail Sales, 1929-33 is the county-level change in retail sales, defined as log difference in retail sales between 1933 and 1929. All these controls are interacted with the After1929 indicator. Finally, in column 6 we control for all of these variables together. Standard errors are clustered at the county level. *,**, and $* * *$ indicate significance at the $10 \%, 5 \%$, and $1 \%$ levels, respectively.

\begin{tabular}{|c|c|c|c|c|c|c|}
\hline & \multicolumn{6}{|c|}{ Ln(\# Independent Patents+1) } \\
\hline & (1) & $(2)$ & $(3)$ & (4) & $(5)$ & (6) \\
\hline BankDistress X After1929 & $\begin{array}{l}-0.082^{* * *} \\
(-2.78)\end{array}$ & $\begin{array}{l}-0.089^{* * *} \\
(-3.04)\end{array}$ & $\begin{array}{l}-0.125^{* * *} \\
(-4.35)\end{array}$ & $\begin{array}{l}-0.126^{* * *} \\
(-4.40)\end{array}$ & $\begin{array}{l}-0.125^{* * *} \\
(-4.34)\end{array}$ & $\begin{array}{l}-0.065^{* *} \\
(-2.22)\end{array}$ \\
\hline Ln(Population, 1920) X After1929 & $\begin{array}{l}-0.092^{* * *} \\
(-6.00)\end{array}$ & & & & & $\begin{array}{l}-0.110^{* * *} \\
(-5.74)\end{array}$ \\
\hline < 6 Banks, 1929 X After1929 & & $\begin{array}{l}0.134^{* * *} \\
(4.92)\end{array}$ & & & & $\begin{array}{l}0.040 \\
(1.30)\end{array}$ \\
\hline Manuf./Pop., 1929 X After1929 & & & $\begin{array}{c}0.002 \\
(1.09)\end{array}$ & & & $\begin{array}{l}0.006^{* * *} \\
(3.61)\end{array}$ \\
\hline Unemployment, 1937 X After1929 & & & & $\begin{array}{l}-0.498 \\
(-0.31)\end{array}$ & & $\begin{array}{l}1.531 \\
(0.80)\end{array}$ \\
\hline Chg Retail Sales, 1929-33, X After1929 & & & & & $\begin{array}{l}-0.041 \\
(-0.64) \\
\end{array}$ & $\begin{array}{l}-0.010 \\
(-0.16) \\
\end{array}$ \\
\hline StateXTime FE & $\mathrm{Y}$ & $\mathrm{Y}$ & $\mathrm{Y}$ & $\mathrm{Y}$ & $\mathrm{Y}$ & $\mathrm{Y}$ \\
\hline County FE & Y & $\mathrm{Y}$ & $\mathrm{Y}$ & $\mathrm{Y}$ & $\mathrm{Y}$ & $\mathrm{Y}$ \\
\hline Start Decade & 1910 & 1910 & 1910 & 1910 & 1910 & 1910 \\
\hline End Decade & 1940 & 1940 & 1940 & 1940 & 1940 & 1940 \\
\hline Adj R-Sq & 0.896 & 0.895 & 0.892 & 0.895 & 0.892 & 0.894 \\
\hline Obs & 11,792 & 11,900 & 11,768 & 11,892 & 11,764 & 11,676 \\
\hline
\end{tabular}


Table 6: The 1917-1920 Agricultural Shock and Innovation during the Great Depression

The table presents estimates from a differences-in-differences regression and shows the relationship between the 1917-1920 agricultural shock and subsequent innovation following the Great Depression. The estimation strategy relies on cross-sectional variation in the shock across U.S. counties within a state. The sample is the near universe of all patents granted by the U.S. Patent and Trademark Office (USPTO) to either U.S. inventors or U.S. firms. The unit of observation is county-decade, for the period 1910-1940. In all columns, the independent variable, CngCommPrice, 1917-1920 X After 1929, is the interaction between After1929 indicator and CngCommPrice, 1917-1920, which is the county-level change from 1917 to 1920 in the international commodity price index calculated for each county, where weights are the crop share of a given farm product out of total county farm output and prices are international farm product prices (Rajan and Ramcharan 2015). In column 1, the dependent variable is the interaction between the After1929 indicator, which equals one for the observations starting from the 1930s decade and onwards, and the Bank Distress indicator, which equals 1 for counties with at least one bank suspension during the Great Depression years of 1930 through 1933, inclusive. In column 2, we limit the sample to independent patents and define the dependent variable as the logarithm of one plus the number of independent patents filed over ten-year periods within each county. Independent are patents by inventors residing in the U.S. that were either unassigned or assigned to individuals at the time of the patent grant date. In columns 3 , the dependent variable is the logarithm of one plus the number of all patents filed over ten-year periods within each county. The estimates of the effect of the agricultural shock on patents are the coefficients on the interaction between CngCommPrice, 1917-1920 and After1929. Standard errors are clustered at the county level. ${ }^{*}, * *$, and ${ }^{* * *}$ indicate significance at the $10 \%, 5 \%$, and $1 \%$ levels, respectively.

\begin{tabular}{lccc}
\hline & $(1)$ & $(2)$ & $(3)$ \\
& BankDistress X After1929 & Ln(\# Ind. Patents+1) & Ln(\# Total Patents+1) \\
\hline CngCommPrice, 1917-1920 X After1929 & $0.029^{* * *}$ & $-0.050^{* * *}$ & $-0.043^{* * *}$ \\
& $(6.53)$ & $(-7.79)$ & $(-6.26)$ \\
\hline StateXTime FE & $\mathrm{Y}$ & $\mathrm{Y}$ & $\mathrm{Y}$ \\
County FE & $\mathrm{Y}$ & $\mathrm{Y}$ & $\mathrm{Y}$ \\
Start Decade & 1910 & 1910 & 1910 \\
End Decade & 1940 & 1940 & 1940 \\
Adj R-Sq & 0.767 & 0.897 & 0.905 \\
Obs & 11,316 & 11,316 & 11,316 \\
\hline
\end{tabular}


Table 7: Bank Distress During the Great Depression and Innovation Quantity in the Long Run

The table shows estimates from a differences-in-differences regression of the number of patents on bank distress during the Great Depression in the long-run. The estimation strategy relies on cross-sectional variation in bank distress across U.S. counties within a state. The sample is the near universe of all patents granted by the U.S. Patent and Trademark Office (USPTO) to either U.S. inventors or U.S. firms. The unit of observation is county-decade, where decades include 1910 through 1990. In column 1, we limit the sample to independent patents and define the dependent variable as the logarithm of one plus the number of independent patents filed over ten-year periods within each county. Independent are patents by inventors residing in the U.S. that were either unassigned or assigned to individuals at the time of the patent grant date. In column 2, we limit the sample to patents assigned to U.S. firms and define the dependent variable as the logarithm of one plus the number of U.S. firm patents filed over ten-year periods within each county. In column 3, the dependent variable is the logarithm of one plus the number of all U.S. patents filed over ten-year periods within each county. Bank Distress is an indicator variable equal to 1 for counties with at least one bank suspension during the Great Depression years of 1930 through 1933, inclusive. In the short run, the estimates of the effect of bank distress on patents are the coefficients on the interaction between Bank Distress and the After1929 indicator, which equals one for the observations starting from the 1930s decade and onwards. In the long run, the estimates of the effect of bank distress on patents are the coefficients on the interaction between Bank Distress and After1939 indicator, which equals one for observations starting with the 1940 decade and onwards. Standard errors are clustered at the county level. *,**, and *** indicate significance at the $10 \%, 5 \%$, and $1 \%$ levels, respectively.

\begin{tabular}{lccc}
\hline & $(1)$ & $(2)$ & $(3)$ \\
& Ln(\# Ind. Pat. +1$)$ & Ln(\# Firm Pat. +1$)$ & Ln(\# Tot. Pat. +1$)$ \\
\hline BankDistress X After1929 & $-0.116^{* * *}$ & 0.014 & $-0.101^{* * *}$ \\
& $(-3.70)$ & $(0.50)$ & $(-3.07)$ \\
BankDistress X After1939 & $-0.094^{* * *}$ & $0.129^{* * *}$ & -0.023 \\
& $(-3.05)$ & $(3.39)$ & $(-0.66)$ \\
\hline StateXTime FE & $\mathrm{Y}$ & $\mathrm{Y}$ & $\mathrm{Y}$ \\
County FE & $\mathrm{Y}$ & $\mathrm{Y}$ & $\mathrm{Y}$ \\
Start Decade & 1910 & 1910 & 1910 \\
End Decade & 1990 & 1990 & 1990 \\
Adj R-Sq & 0.863 & 0.857 & 0.875 \\
Obs & 26,775 & 26,775 & 26,775 \\
\hline
\end{tabular}


Table 8: Bank Distress During the Great Depression and Innovation Quality

The table shows estimates from a differences-in-differences regression looking at changes in patent quality metrics following the Great Depression. The estimation strategy relies on cross-sectional variation in bank distress across U.S. counties within a state. The sample is the near universe of all patents granted by the U.S. Patent and Trademark Office (USPTO) to either U.S. inventors or U.S. firms. The sample of future patent citations includes all patents granted by the USPTO, including independent, U.S firm and non-U.S. patents. The unit of observation is county-decade, for the period 1910-1940. In column 1, the dependent variable is the logarithm of one plus the total number of future patent citations citing all independent patents filed over each ten-year period within a county. Independent are patents by inventors residing in the U.S. that were either unassigned or assigned to individuals at the time of the patent grant date. In column 2, we repeat the same analysis looking at all patents (firms and independent inventors). In column 3, we instead look at the (logarithm plus one) of the average number of citations received by independent patents. In column 4, we repeat the same analysis looking at all patents. Bank Distress is an indicator variable equal to 1 for counties with at least one bank suspension during the Great Depression years of 1930 through 1933, inclusive. The estimates of the effect of bank distress on patents are the coefficients on the interaction between Bank Distress and the After1929 indicator, which equals one for the observations starting from the 1930s decade and onwards. Standard errors are clustered at the county level. *, **, and *** indicate significance at the $10 \%, 5 \%$, and $1 \%$ levels, respectively.

\begin{tabular}{lcccc}
\hline & $\begin{array}{c}(1) \\
\text { Ind. \# Cit }\end{array}$ & $\begin{array}{c}(2) \\
\text { Tot. \# Cit }\end{array}$ & $\begin{array}{c}(3) \\
\text { Ind. Avg Citations }\end{array}$ & $\begin{array}{c}(4) \\
\text { Tot. Avg Citations }\end{array}$ \\
\hline BankDistress X After1929 & 0.013 & 0.031 & $0.137^{* * *}$ & $0.125^{* * *}$ \\
& $(0.29)$ & $(0.67)$ & $(4.98)$ & Y \\
\hline StateXTime FE & Y & Y & Y & Y \\
County FE & Y & Y & Y & 1910 \\
Start Decade & 1910 & 1910 & 1910 & 1940 \\
End Decade & 1940 & 1940 & 1940 & 0.398 \\
Adj R-Sq & 0.802 & 0.825 & 0.368 & 11,900 \\
Obs & 11,900 & 11,900 & 11,900 & \\
\hline
\end{tabular}


Table 9: Bank Distress During the Great Depression and Quality Distribution

The table shows estimates from a differences-in-differences regression looking at quality metrics. The estimation strategy relies on cross-sectional variation in bank distress across U.S. counties within a state. The sample is the near universe of all patents granted by the U.S. Patent and Trademark Office (USPTO) to either U.S. inventors or U.S. firms. The sample of future patent citations includes all patents granted by the USPTO, including independent, U.S firm and non-U.S. patents. The unit of observation is county-decade, for the period 1910-1940. In column 1, the dependent variable is the total number of independent patents in the top $1 \%$ of the citation distribution of the corresponding technology class during 1910-1940 that were filed in the county-decade. In column 2, the dependent variable is the total number of independent patents in the bottom $99 \%$ of the citation distribution of the corresponding technology class during 1910-1940 that were filed in the county-decade. In column 3 and 4, we construct equivalent outcomes but looking at the top $10 \%$ and bottom $90 \%$, and in 5 and 6 the same for top $25 \%$ and bottom $75 \%$. The outcome is always transformed as logarithm plus one. Bank Distress is an indicator variable equal to 1 for counties with at least one bank suspension during the Great Depression years of 1930 through 1933, inclusive. The estimates of the effect of bank distress on patents are the coefficients on the interaction between Bank Distress and the After1929 indicator, which equals one for the observations starting from the 1930s decade and onward. We control for population in 1920 interacted with the After1929 indicator in all columns. Standard errors are clustered at the county level. *, ${ }^{* *}$, and ${ }^{* * *}$ indicate significance at the $10 \%, 5 \%$, and $1 \%$ levels, respectively.

\begin{tabular}{lcccccc}
\hline & $(1)$ & $(2)$ & $(3)$ & $(4)$ & $(5)$ & $(6)$ \\
& Top 1\% & Bot. 99\% & Top 10\% & Bot. 90\% & Top. 25\% & Bot. 75\% \\
\hline BankDistress X After1929 & 0.012 & $-0.083^{* * *}$ & -0.013 & $-0.083^{* * *}$ & $-0.048^{*}$ & $-0.099^{* * *}$ \\
& $(1.08)$ & $(-2.82)$ & $(-0.63)$ & $(-2.83)$ & $(-1.89)$ & $(-3.35)$ \\
\hline StateXTime FE & Y & Y & Y & Y & Y & Y \\
County FE & Y & Y & Y & Y & Y & Y \\
Start Decade & 1910 & 1910 & 1910 & 1910 & 1910 & 1910 \\
End Decade & 1940 & 1940 & 1940 & 1940 & 1940 & 1940 \\
Adj R-Sq & 0.754 & 0.895 & 0.839 & 0.892 & 0.871 & 0.883 \\
Obs & 11,792 & 11,792 & 11,792 & 11,792 & 11,792 & 11,792 \\
\hline
\end{tabular}


Table 10: Bank Distress During the Great Depression and Individual Inventor Patenting During the 1930s among Independent Inventors of the 1920s

The table examines the potential reallocation of independent inventors into firms during the 1930s in counties with greater bank distress during the Great Depression. The estimation strategy relies on crosssectional variation in bank distress across U.S. counties within a state. To test for reallocation, we limit the sample to individual U.S. inventors who: 1) had at least one independent patent granted by the U.S. Patent and Trademark Office (USPTO) during the 1920s; and 2) had at least one patent granted during the 1930s; and 3) we could find the inventor in 1920 or 1930 censuses (to assign the inventor's location during the Depression, we use the location in the 1930 Census and, when this is not available, the location in the 1920 Census). Independents are patents by inventors residing in the U.S. that were either unassigned or assigned to individuals at the time of the patent grant date. In all columns, the dependent variable equals 1 if the inventor obtains at least one patent assigned to a U.S. firm in the 1930s, and 0 if he obtains at least one independent patent in the 1930s. Column 1 includes state fixed effects. Column 2 adds additional county-level controls (log of population in 1920), while column 3 adds a set of individual-level controls based on the 1920 Census (homeownership, log of inventor age, status as an entrepreneur, and gender). Bank Distress \% is defined at the county-level and equal to the ratio of bank deposits at banks suspended between 1930 and 1933 divided by total banks deposits in 1929. The results with other definitions of bank distress variable are in Table A.13. Standard errors are clustered at the county level. *, **, and $* * *$ indicate significance at the $10 \%, 5 \%$, and $1 \%$ levels, respectively.

\begin{tabular}{lccc}
\hline & \multicolumn{3}{c}{ Patent in Firm in 1930s } \\
\cline { 2 - 4 } & $(1)$ & $(2)$ & $(3)$ \\
\hline Bank Distress>Med & $0.020^{*}$ & $0.025^{* *}$ & $0.024^{* *}$ \\
& $(1.69)$ & $(2.07)$ & $(2.05)$ \\
\hline State FE & $\mathrm{Y}$ & $\mathrm{Y}$ & $\mathrm{Y}$ \\
Patent Post & $\mathrm{Y}$ & $\mathrm{Y}$ & $\mathrm{Y}$ \\
Pre Ind Pat & $\mathrm{Y}$ & $\mathrm{Y}$ & $\mathrm{Y}$ \\
County Controls & $\mathrm{N}$ & $\mathrm{N}$ & $\mathrm{Y}$ \\
Ind. Controls & $\mathrm{N}$ & 0.020 & 0.026 \\
Adj R-Sq & 0.019 & 5,294 & 5,294 \\
Obs & 5,295 & & \\
\hline
\end{tabular}


Table 11: Bank Distress During the Great Depression and Individual Inventor Geographic Mobility During the 1930s

The table examines the potential geographic mobility of inventors away from counties with greater bank distress during the Great Depression. The estimation strategy relies on cross-sectional variation in bank distress across U.S. counties within a state. To test for geographic mobility, we limit the sample to individual U.S. inventors who had at least one patent granted by the U.S. Patent and Trademark Office (USPTO) during the 1930s. In all columns, the dependent variable equals 1 if the inventor' county in the 1940 complete count Census is different from the county where he lived as of the 1920 Census. Bank Distress is an indicator variable equal to 1 for counties with at least one bank suspension during the Great Depression years of 1930 through 1933, inclusive. Bank Distress \% is defined at the county-level and equal to the ratio of bank deposits at banks suspended between 1930 and 1933 divided by total banks deposits in 1929. Bank Distress > Median is an indicator variable equal to 1 for counties with an above median \% of deposits in suspended banks, calculated as the cumulative deposits in bank suspended from 1930 through 1933 as a share of bank deposits in 1929. Standard errors are clustered at the county level. $*, * *$, and $* * *$ indicate significance at the $10 \%, 5 \%$, and $1 \%$ levels, respectively.

\begin{tabular}{lccc}
\hline & \multicolumn{3}{c}{ Inter-County Move in 1930s } \\
\cline { 2 - 4 } & $(1)$ & $(2)$ & $(3)$ \\
\hline Bank Distress >Med & -0.002 & \\
Bank Distress \% & $(-0.21)$ & 0.026 & \\
& & $(1.30)$ & 0.003 \\
Bank Distress & & $(0.30)$ \\
\hline State FE & & $\mathrm{Y}$ \\
Patent Pre & $\mathrm{Y}$ & $\mathrm{Y}$ \\
Controls & $\mathrm{Y}$ & $\mathrm{Y}$ & $\mathrm{Y}$ \\
Adj R-Sq & $\mathrm{Y}$ & $\mathrm{Y}$ & 0.030 \\
Obs & 0.030 & 0.030 & 66,693 \\
\hline
\end{tabular}

